\title{
Aureochrome 1a Is Involved in the Photoacclimation of the Diatom Phaeodactylum tricornutum
}

\author{
Benjamin Schellenberger Costa ${ }^{1 * 9}$, Matthias Sachse ${ }^{29}$, Anne Jungandreas ${ }^{1}$, Carolina Rio Bartulos ${ }^{2}$, \\ Ansgar Gruber ${ }^{2 x}$, Torsten Jakob ${ }^{1}$, Peter G. Kroth ${ }^{2}$, Christian Wilhelm ${ }^{1}$
}

1 Institut für Biologie, Universität Leipzig, Leipzig, Germany, 2 Fachbereich Biologie, Universität Konstanz, Konstanz, Germany

\begin{abstract}
Aureochromes constitute a family of blue light (BL) receptors which are found exclusively in heterokont algae such as diatoms (Bacillariophyceae) and yellow-green algae (Xanthophyceae). Previous studies on the diatom Phaeodactylum tricornutum indicate that the formation of a high light acclimated phenotype is mediated by the absorption of BL and that aureochromes might play an important role in this process. P. tricornutum possesses four genes encoding aureochromes. In this study we confirm the nuclear localisation of the PtAUREO1a, $1 \mathrm{~b}$ and 2 proteins. Furthermore we studied the physiology of light quality acclimation in genetically transformed $P$. tricornutum cell lines with reduced expression of the aureochrome 1a gene. The results demonstrate that the AUREO1a protein has a distinct function in light acclimation. However, rather unexpectedly AUREO1a seems to repress high light acclimation which resulted in a state of 'hyper' high light acclimation in aureo1a silenced strains. This was indicated by characteristic changes of several photosynthetic parameters, including increased maximum photosynthesis rates, decreased chlorophyll a contents per cell and increased values of nonphotochemical quenching in AUREO1a silenced strains compared to wild type cultures. Strikingly, AUREO1a silenced strains exhibited phenotypic differences compared to wild type cells during cultivation under BL as well as under red light (RL) conditions. Therefore, AUREO1a might influence the RL signalling process, suggesting an interaction of AUREO1a with RL perception pathways.
\end{abstract}

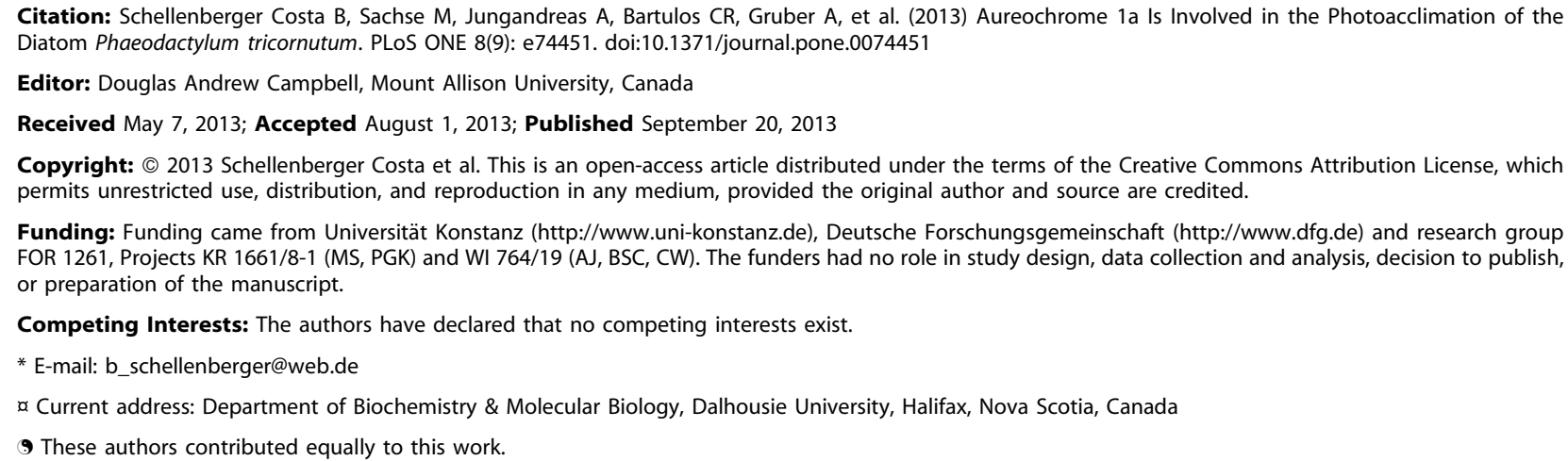

Citation: Schellenberger Costa B, Sachse M, Jungandreas A, Bartulos CR, Gruber A, et al. (2013) Aureochrome 1a Is Involved in the Photoacclimation of the Diatom Phaeodactylum tricornutum. PLoS ONE 8(9): e74451. doi:10.1371/journal.pone.0074451

Editor: Douglas Andrew Campbell, Mount Allison University, Canada

Received May 7, 2013; Accepted August 1, 2013; Published September 20, 2013

Copyright: (C) 2013 Schellenberger Costa et al. This is an open-access article distributed under the terms of the Creative Commons Attribution License, which permits unrestricted use, distribution, and reproduction in any medium, provided the original author and source are credited.

Funding: Funding came from Universität Konstanz (http://www.uni-konstanz.de), Deutsche Forschungsgemeinschaft (http://www.dfg.de) and research group FOR 1261, Projects KR 1661/8-1 (MS, PGK) and WI 764/19 (AJ, BSC, CW). The funders had no role in study design, data collection and analysis, decision to publish, or preparation of the manuscript.

Competing Interests: The authors have declared that no competing interests exist.

* E-mail: b_schellenberger@web.de

a Current address: Department of Biochemistry \& Molecular Biology, Dalhousie University, Halifax, Nova Scotia, Canada

9 These authors contributed equally to this work.

\section{Introduction}

Diatoms are unicellular microalgae which contribute significantly to the global carbon, nitrogen, phosphorus and silica cycles $[1,2,3]$. Although present in nearly all aquatic habitats, diatoms are particularly abundant in cold climates and tend to dominate turbulent and nutrient rich ocean waters. In its natural habitat, phytoplankton is exposed to large variations of light intensity [4] and light quality $[5,6]$. Hence, the photoprotective capacity of phytoplankton cells is believed to be an important functional trait of microalgal ecology in the aquatic environment [7]. Diatoms as a phytoplankton group show an extraordinary high capacity to dissipate excessively absorbed light energy safely as heat by nonphotochemical quenching (NPQ) $[8,9]$ and the evolutionary success of diatoms is thought to be closely linked to their ability to cope with these dynamic light conditions $[10,11]$. In diatoms, the extent of NPQ is closely correlated to the activity of the xanthophyll cycle (XC) and thus determined by the concentration of the XC pigment diatoxanthin (Dtx) [12].

Considerable progress was made in diatom molecular biology since the development of genetic transformation techniques for diatoms [13] and the sequencing of the genomes of Thalassiosira pseudonana and Phaeodactylum tricornutum $[14,15]$. Still, the molecular basis of light perception in diatoms remains enigmatic [10]. In contrast, the understanding of photoacclimation and its underlying molecular mechanisms is far more comprehensive in higher plants and in green algae. The reduction state of the plastoquinone pool as well as the reduction states of the thioredoxin system and other stromal redox pools are thought to be the major regulators of photoacclimation in the green lineage $[16,17,18,19]$. The signal transduction of these processes is modulated by several other systems, which perceive for example the evolution of reactive oxygen species, the ATP to ADP ratio or the extend of the proton gradient across the thylakoid membrane [20]. Interestingly, to current knowledge photoreceptors are assumed to be of minor importance for the photoacclimation of green algae and higher plants [16,21]. In contrast, in diatoms photoreceptors may play a more important role for photoacclimation. Coesel et al. [22] characterised cryptochrome $P t \mathrm{CPF} 1$ overexpression lines of $P$. tricornutum, which exhibited altered transcription levels of several photoacclimation associated genes involved in carotenoid and chlorophyll biosynthesis and in photoprotection.

Three families of photoreceptors have been identified in diatoms, the red light (RL) absorbing phytochromes as well as 
the blue light (BL) absorbing cryptochromes and a recently discovered family of BL photoreceptors named aureochromes $[10,23,24]$. Phytochromes and cryptochromes are widely distributed within eukaryotes, whereas aureochromes are restricted to the stramenopiles [25]. Aureochromes possess an N-terminal DNA binding basic zipper (bZIP) domain and a flavin containing Cterminal LOV (light, oxygen, voltage) domain [23]. Heterologous expression of two aureochromes (VfAUREO1/VfAUREO2) of the multicellular xanthophyte Vaucheria frigida as GFP fusion proteins in onion epidermis revealed partial and absolute nuclear localisation, respectively. This, together with the presence of a bZIP domain, supported the notion that aureochromes might represent light regulated transcription factors [23,26]. Furthermore, knockdown-experiments revealed that VfAUREOl and VfAUREO2 are involved in the induction of branching and the development of the branch primordials into sexual organs, respectively [23]. However, the biological function of aureochromes in unicellular stramenopiles such as diatoms is still unknown. A recent analysis of the $P$. tricornutum AUREOla LOV and LOV-J $\alpha$ domains demonstrated the BL-dependent dimerisation of the LOV-J $\alpha$ domain [26], which is a prerequisite for bZIPdependent DNA binding. Furthermore, it was shown that AUREOla is involved in transcriptional regulation of the cell cycle protein dsCYC2 in $P$. tricornutum and facilitates the transition of the Gl checkpoint of the cell cycle [27]. These data indicate that aureochromes are acting as transcription factors and are involved in the regulation of mitosis in unicellular stramenopiles and in the regulation of photomorphogenesis in multicellular stramenopiles. In $P$. tricornutum four different genes encoding aureochromes have been identified [10].

In a previous study we have shown that photoreceptors are involved in the processes of photoacclimation and photoprotection in diatoms [28]. Cultivation of P. tricornutum under low irradiance of $\mathrm{BL}$ induced the generation of a high light-adapted phenotype whereas a low light-adapted phenotype was observed for cultures grown under equivalent amounts of red light (RL). The high lightadapted phenotype was characterised by increased maximum photosynthesis rates and an enhanced photoprotective potential. The latter was concluded from an increased NPQ capacity, a larger pool of $\mathrm{XC}$ pigments and a higher de-epoxidation state of $\mathrm{XC}$ pigments after excess illumination in cultures grown under BL conditions in comparison to cultures grown under RL conditions. These results indicated that the acclimation to high irradiance relies on a BL-mediated photoacclimation in P. tricornutum.

It was further shown that under BL conditions several thylakoid membrane proteins were up-regulated compared to RL conditions. Interestingly, the promoter regions of the respective genes exhibited a comparatively high frequency of potential aureochrome binding motives (as inferred from VfAUREO1) whereas no such motives were found upstream of genes which were upregulated under RL conditions [28]. It was speculated that a blue light activated form of an aureochrome of $P$. tricornutum would act as an inducer or enhancer of high light photoacclimation. Consequently, aureochrome silenced strains should exhibit a reduced high light photoacclimation under BL and WL conditions and should perform similarly as wild type (WT) cells grown under RL conditions.

The aims of the present study were to test this hypothesis and to determine the localisation of aureochromes in P. tricornutum in vivo. For this purpose, the intracellular localisation of aureochromes was studied by employing full length protein-GFP fusion proteins of three $P$. tricornutum aureochromes. Furthermore, AUREOla silencing cell lines were generated and their physiological responses to cultivation under limiting and moderate intensities of BL and RL were investigated. To differentiate between light intensity and light quality driven reactions, the applied experimental design ensured that identical amounts of quanta were absorbed by the cells under BL and RL conditions, respectively.

\section{Materials and Methods}

\section{Phylogenetic Analysis}

The dataset includes 32 currently available aureochrome sequences of stramenopiles from the National Center for Biotechnology Information (NCBI; http://www.ncbi.nlm.nih. gov/) or the Joint Genome Institute (JGI; http://genome.jgi-psf. org//) genome databases. For amino acid sequence alignments the ClustalW web application at GenomeNet (http://www.genome. jp/tools/clustalw/) was used and the default settings for slow/ accurate alignment and the output format Phylip were chosen. The alignment was manually refined, yielding 360 amino acid positions (Figure S1). Maximum likelihood analyses by the web application PhyML (http://www.atgc-montpellier.fr/phyml/) were conducted [29]; the substitution model LG [30] was selected with four substitution rate categories. Bootstrap analyses of 100 replicates were performed. Only bootstrap values above 50 are shown in the phylogenetic tree. The resulting tree was imported in the web application FigTree v1.1.2 (http://tree.bio.ed.ac.uk/ software/figtree/). Radial tree layout was chosen.

\section{Cultivation of Algae for Transformation and Screening}

The axenic Phaeodactylum tricornutum Bohlin (CCAP 3/55; UTEX 646) culture was obtained from the culture collection of algae of the University of Texas at Austin (Austin, Tx, USA). P. tricornutum was cultivated in f/2 medium according to Guillard and Lorenzen [31] with half of the original salt content and without added silica. Cells were grown under continuous shaking at $20^{\circ} \mathrm{C}$ in a $16 \mathrm{~h} / 8 \mathrm{~h}$ day/night cycle at $35 \mu \mathrm{mol}$ photons $\mathrm{m}^{-2} \mathrm{~s}^{-1}$. Solid media contained 1.2\% (w/v) Bacto Agar (BD, Sparks, MD, USA) and plated cultures were cultivated under continuous illumination at $75 \mu \mathrm{mol}$ photons $\mathrm{m}^{-2} \mathrm{~s}^{-1}$.

\section{RNA Extraction and cDNA Generation}

Cells were harvested by centrifugation at $5000 \mathrm{~g}$ for $5 \mathrm{~min}$. Pellets were frozen in liquid nitrogen and pestled. Powdered cells were treated with RNA extraction reagent $\left(\mathrm{TRIzol}^{\circledR}\right.$ reagent, Life Technologies, Darmstadt, Germany) according to the manufacturer's instructions. Upon obtaining the aqueous phase the protocol was modified by applying the aqueous phase to a RNA affinity spin column (RNeasy ${ }^{\circledR}$ spin column; Qiagen, Hilden, Germany) in order to minimise contamination with DNA. cDNA was generated according to the manufacturer's instructions by using a reverse transcription kit (Reverse Transcription System, Promega, Mannheim, Germany).

\section{Generation of GFP-AUREO Fusion Constructs}

For the generation of c-terminal GFP fusion proteins full length sequences without stop codon of P. tricornutum AUREO1a (49116), AUREO1aSig (56684), AUREO1b (49458) and AUREO2 (56688) were amplified from cDNA by blunt end PCR [32] with unmodified primers (Table S1) using a Mastercycler ep gradient (Eppendorf, Hamburg, Germany). Numbers in parentheses correspond to protein IDs of the Joint Genome Institute (JGI) database of $P$. tricornutum v2.0 (http://genome.jgi-psf.org/Phatr2/ Phatr2.home.html). The original pPha-T1 P. tricornutum transformation vector (GenBank AF2 19942) [33] was modified to contain a StuI restriction site followed by a GFP sequence as described previously [34]. Furthermore, a slightly modified vector was 
constructed by mutating the GFP START-codon to GGA. The full length $A U R E O$ sequences were cloned into both variants of the pPha-T1-GFP transformation vector in frame with GFP. All fusion-constructs were sequenced (GATC Biotech AG, Konstanz, Germany) from their $5^{\prime}$ and $3^{\prime}$ end to verify correct cloning.

\section{Nuclear Transformation of $P$. tricornutum}

Nuclear transformation of $P$. tricornutum was performed using a Bio-Rad Biolistic PDS-1000/He Particle Delivery System (BioRad, Hercules, CA, USA) fitted with 900/1100/1350 psi rupture disks as described previously [13,35]. For selective cultivation of $P$. tricornutum transformants $75 \mu \mathrm{g} \mathrm{ml}^{-1}$ Zeocin (Invitrogen, Carlsbad, CA, USA) were added to the solid f/2 media according to Guillard and Lorenzen [31].

\section{Microscopy of Aureochrome:GFP Fusion Expressing $P$. tricornutum cell lines}

Cells were observed using an Olympus BX51 epifluorescence microscope equipped with a Zeiss AxioCam MRm digital camera system (Carl Zeiss MicroImaging GmbH, Göttingen, Germany). Differential interference contrast illumination (DIC) was used in order to obtain transmitted light images. Chlorophyll autofluorescence and GFP fluorescence of transformants were dissected using the mirror unit UMWSG2 (Olympus) and the filter set 41020 (Chroma Technology Corp, Rockingham, VT, USA), respectively. Multichannel fluorescence pictures were recorded and assembled with the software AxioVision Rel. 4.6 (Carl Zeiss Microscopy $\mathrm{GmbH}$, Göttingen, Germany). Micrographs were size calibrated using a stage micrometer.

Additionally, images were acquired with a confocal laser scanning microscope LSM 510 META (Carl Zeiss MicroImaging GmbH, Göttingen, Germany) using a Plan-Apochromat 63x/ 1.4 Oil DIC objective. GFP fluorescence and chlorophyll autofluorescence were excited at $488 \mathrm{~nm}$, Hoechst 33342 DNA stain fluorescence was excited at $405 \mathrm{~nm}$, filtered with a beam splitter (HFT 405/488/543), and detected by three different photomultipliers with a band-pass filter (BP 505-530) for GFP fluorescence, a low pass filter (LP 650) for chlorophyll autofluorescence and a band pass filter (BP 470-500) for Hoechst 33342 DNA stain. For multichannel image acquisition of DIC, GFP fluorescence, chlorophyll autofluorescence and Hoechst 33342 DNA stain fluorescence the software ZEN 2009 was used. For each image z-stacks of 20 pictures were acquired. Maximum intensity zprojections were calculated from slices of image stacks to ensure complete detection of fluorochromes within a cell. Additionally, orthoview analysis of nuclear GFP-co-localisation was performed (Figure S2).

\section{Generation of an AUREO1a Silencing Construct}

For the design of the AUREOla silencing construct, a $120 \mathrm{bp}$ long unique nucleotide sequence of AUREOla was identified (bp 982-1101). For verification of the AUREOla specificity, nucleotide BLAST analyses in the genome of $P$. tricornutum were conducted in the corresponding databases of the JGI and NCBI. The nucleotide sequence was synthesised (Eurofins MWG Operon, Ebersberg, Germany) as part of a synthetic gene construct in the vector backbone pCR2.1 in sense orientation adding three restriction sites: sticky restriction sites XbaI followed by $\mathrm{KpnI}$ to the $5^{\prime}$-end and a blunt restriction site HpaI to the $3^{\prime}$ end (Figure S3). The vector was amplified in Escherichia coli XL1 Blue (Agilent Technologies, Waldbronn, Germany) and isolated (QIAprep ${ }^{\circledR}$ Spin Miniprep Kit). Mixed sticky and blunt end restriction digestions were performed with $\mathrm{KpnI}$ and HpaI in order to obtain the AUREO1a fragment for sense orientation and with $\mathrm{XbaI}$ and $\mathrm{HpaI}$ in order to obtain the AUREO1a fragment for antisense orientation.

The loop region of the RNAi construct consisted of the second intron of the P. tricormutum NTT1 gene (49533), which was cloned into the shuttle vector pPha-NR (GenBank accession no. JN180663 [36]; kindly provided by Stefan Zauner/Philipps Universität Marburg). Additional restriction sites were added to the vector (Figure S4). pPha-NR contains the promoter region of the $P$. tricornutum homologue of the nitrate reductase, which was shown to be inducible by nitrate availability in the diatoms Cylindrotheca fusiformis and Thalassiosira pseudonana [37,38]. The target vector was cut by a mixed sticky and blunt end restriction digestion with $\mathrm{KpnI} / \mathrm{HpaI}$. The sense fragment of AUREO1a was inserted upstream of the loop region into the $\mathrm{KpnI} / \mathrm{HpaI}$ digested target vector. This process was repeated employing $\mathrm{XbaI}$ and StuI for the mixed digest of the target vector carrying the sense fragment in order to introduce the second fragment in antisense orientation downstream of the loop region of the target vector to generate the final construct (Figure 1). Constructs were sequenced (GATC Biotech AG, Konstanz, Germany) after each cloning step from $5^{\prime}$ and/or $3^{\prime}$ end of the inserts to ensure correct cloning. Subsequently, nuclear transformation of $P$. tricornutum was performed as described above.

\section{Screening of AUREO1a Silenced Cell Lines}

Small amounts of cell material were collected with sterile toothpicks and suspended in $50 \mu \mathrm{l}$ distilled water. The samples were subjected to three freeze $\left(-20^{\circ} \mathrm{C}\right.$ for $\left.30 \mathrm{~min}\right)$ and thaw (room temperature) cycles. Subsequently, samples were incubated at $95^{\circ} \mathrm{C}$ for $10 \mathrm{~min} .1 \mu \mathrm{l}$ of each sample was taken as template for standard PCR amplification with a total volume of $12.5 \mu \mathrm{l}$. Primers annealing in the nitrate reductase promoter of the vector and in the corresponding downstream region of the silencing construct were used (Table S1). PCR products were screened for the occurrence of signals with an amplicon length of $400 \mathrm{bp}$ indicating the insertion of an AUREOla silencing construct.

Positive clones were cultivated in $50 \mathrm{ml}$ Erlenmeyer flasks in f/2 medium with half of the original salt content and without silica. In addition to growth with $\mathrm{NaNO}_{3}$ as sole nitrogen source, each clone was further cultivated in modified $\mathrm{f} / 2$ medium with $0.88 \mathrm{mM} \mathrm{NH} 4 \mathrm{Cl}$ substituting $\mathrm{NaNO}_{3}$. Cultures were grown at an incident irradiation of $35 \mu \mathrm{mol}$ photons $\mathrm{m}^{-2} \mathrm{~s}^{-1}$ white light emitted by fluorescence tubes $(18 \mathrm{~W} / 865$, Osram, Munich, Germany) and a day/night rhythm of $16 \mathrm{~h} / 8 \mathrm{~h}$ until they exhibited a Chl $a$ content of approximately $2 \mu \mathrm{g} \mathrm{ml}^{-1}$. Cultures were always harvested at the same time of the day via centrifugation $\left(6 \mathrm{~min}, 3400 \mathrm{~g}, 4^{\circ} \mathrm{C}\right)$. Cell pellets were frozen in liquid nitrogen and stored at $-80^{\circ} \mathrm{C}$ until further use.

\section{Protein Isolation and Immunoblotting}

For protein extraction, cell pellets were resuspended in $100 \mu \mathrm{l}$ isolation buffer (50 mM Tris HCL, pH 8.0) supplemented with protease inhibitor (Complete ${ }^{\mathrm{TM}}$ EDTA-free, Roche, Grenzach Wyhlen, Germany) according to the manufactures instruction. Cells were disrupted by ultrasonification at $4^{\circ} \mathrm{C}$. Afterwards, samples were centrifuged for $30 \mathrm{~min}$ at $12,000 \mathrm{~g}$ and $4^{\circ} \mathrm{C}$ in order to remove cell debris and unbroken cells. The protein concentration of the supernatant was determined via fluorometric protein quantification (Qubit ${ }^{\circledR}$ protein assay kit) according to the manufacturer's instructions.

Proteins were separated on $12 \%$ polyacrylamid gels by one dimensional SDS-PAGE according to Laemmli et al. [39]. $15 \mu \mathrm{g}$ protein were loaded in each lane if not stated otherwise. 

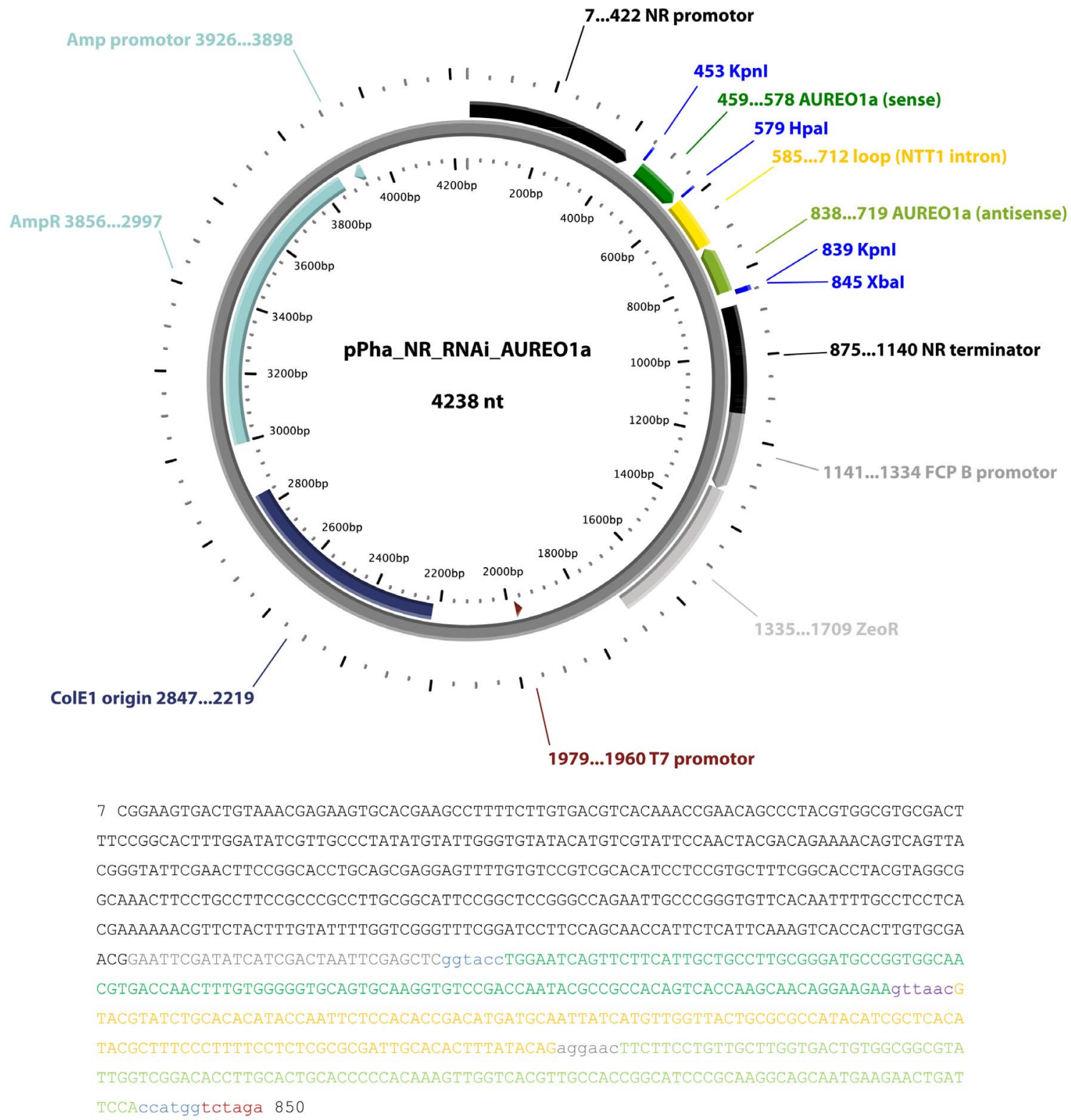

Figure 1. Vector map of the aureochrome 1a silencing construct. The sequence of the NR promoter controlled hairpin construct is given. The sequence is colour coded corresponding to the vector map: NR promoter (black), aureochrome 1a sense (intense green), NTT1 intron (yellow) and aureochrome 1a antisense (light green). Active and inactively fused restriction sites are given in small letters in colour coding: Kpnl (light blue), Hpal (purple), inactive fusion of Stul and Hpal (grey) and Xbal (dark red). doi:10.1371/journal.pone.0074451.g001

Immunoblots were performed as described in Gallagher et al. [40] using an AUREOla specific peptide antibody (Agrisera AB, Vännäs, Sweden). For the generation of the peptide antibody, the amino acid sequence positions 46-59 of AUREOla was chosen. The sequence of the synthetic peptide used for immunisation was slightly modified to allow coupling to a carrier protein by adding an N-terminal cysteine: $\left(\mathrm{H}_{2} \mathrm{~N}-\right)$ CSEQKEELLNSGERE ($\mathrm{CONH}_{2}$ ). The specificity of the peptide was controlled by a protein BLAST in the JGI database of $P$. tricornutum, which yielded only one non-redundant hit for AUREOla (settings: Expect: 1.0 E-1; Wordsize: 3; Filter low complexity regions: activated; Perform gapped alignment: deactivated; Scoring Matrix: BLOSUM62). An identical SDS-PAGE was prepared in parallel to serve as loading control and stained with colloidal Coomassie
(Roti ${ }^{\circledR}$ Blue, Roth, Karlsruhe, Germany) according to the manufacturer's instructions allowing the estimation of the protein content per lane and correct loading of proteins. Successful transfer of the protein samples was confirmed by reversible protein staining of the nitrocellulose membrane with Ponceau S (Roth, Karlsruhe, Germany) and by staining the blotted gels with colloidal Coomassie according to the manufacture's instructions.

\section{Cultivation of Algae for Physiological Measurements}

For physiological measurements, WT $P$. tricornutum and aureochrome la silenced strains aureo1a-15 and aureo1a-50 were cultivated as described in Schellenberger Costa et al. [28]. Algae were grown semi-continuously in an air-lifted rectangular bioreactor with a depth of $3 \mathrm{~cm}$ and a maximal volume of $2.5 \mathrm{l}$. The 
temperature was set to $20^{\circ} \mathrm{C}$. For cultivation, f/2 medium with half of the original salt content and without silica was used. Algal cultures were maintained at a Chl $a$ concentration of about $2 \mu \mathrm{g}$ $\mathrm{ml}^{-1}$. Prior to the measurements, algae were adapted to the specific light conditions for at least one week. Each strain was grown under limiting (LL) and medium light (ML) intensities of blue $(469 \pm 10 \mathrm{~nm} ; \mathrm{BL})$ or red light $(659 \pm 11 \mathrm{~nm} ; \mathrm{RL})$ at a day/ night rhythm of $14 \mathrm{~h} / 10 \mathrm{~h}$. Incident irradiance of BL and RL was carefully adjusted to yield the same amount of photosynthetically absorbed radiation (Q $Q_{\text {Phar }}$ ) according to Gilbert et al. [41] for all cell suspensions grown under LL and ML conditions, respectively. For LL conditions, cultures were adjusted to a $Q_{\text {Phar }}$ of $10 \mu \mathrm{mol}$ photons $\mathrm{m}^{-2} \mathrm{~s}^{-1}$. For ML conditions, cultures were adjusted to a $Q_{\text {Phar }}$ of $30 \mu \mathrm{mol}$ photons $\mathrm{m}^{-2} \mathrm{~s}^{-1}$. The calculation of $Q_{\text {Phar }}$ requires the determination of the Chl $a$-specific in vivo absorption coefficient ( $a^{*}$ Phy $)$ and of the emission spectra of the source of irradiation. The emission spectra of the blue and red LED panels (CLF plants, Wertingen, Germany) used for illumination were measured with a spectroradiometer (Tristan, Hamburg, Germany). Due to differences of the $\mathrm{a}^{*}$ Phy between aureochrome la silenced strains and WT cells under ML conditions, the amount of applied incident irradiance had to be specifically adjusted for the different strains in order to obtain equal amounts of $Q_{P h a r}$ in the semi-continuous cultures which were used for the physiological measurements. Details of the specific intensity of the incident irradiance are presented in Table 1.

Data on WT cells grown under identical conditions were previously presented and discussed in Schellenberger Costa et al. [28]. The same data serve as reference for the consecutively measured data on the aureo 1 a silenced strains obtained in this study and are included where appropriate for convenient comparison.

\section{Cellular Parameters}

The determination of Chl a concentration was performed spectrometrically after extraction with $90 \%$ acetone according to Wagner et al. [42] using the equations of Jeffrey and Humphrey [43]. Cell numbers were measured with a particle counter (Z2, Beckman Coulter, Krefeld, Germany). Growth rates were calculated from the daily increase of Chl $a$. These growth rates are identical to those based on daily increase of cell number since the Chl $a$ content per cell was constant within each culturing condition. In vivo absorption spectra were measured with a scattering corrected spectrophotometer (M500, Zeiss, Jena, Germany) adjusted to a bandwidth of $1 \mathrm{~nm}$. Cellular dry weight was determined according to $\mathrm{Su}$ et al. [44]. The carbon-related biomass production $\left(\mathrm{B}_{\mathrm{C}}\right)$ and the quantum requirement of carbon fixation $\left(1 / \Phi_{\mathrm{C}}\right)$ were calculated as described in $\mathrm{Su}$ et al. [44].

\section{Photosynthesis Rates and Non-photochemical Quenching}

Oxygen-based photosynthesis rates and fluorescence parameters were measured simultaneously as described in Wagner et al. [42]. Non-photochemical quenching (NPQ) was calculated according to Bilger and Björkman [45].

\section{Pigment Isolation}

For determination of diadinoxanthin (Ddx) concentration, $10 \mathrm{ml}$ of dark adapted culture were harvested on a glass fibre filter, frozen in liquid nitrogen and freeze-dried over night (Labconco FreeZone, ILMVAC GmbH, Illmenau, Germany). Pigment extraction and HPLC analysis were performed as described in $\mathrm{Su}$ et al. [44]. For determination of Ddx deepoxidation after excess light illumination, samples were illumi- nated with $1000 \mu \mathrm{mol}$ photons $\mathrm{m}^{-2} \mathrm{~s}^{-1}$ white light for $10 \mathrm{~min}$ and frozen in liquid nitrogen prior to freeze-drying. The deepoxidation state (DES) was calculated as the ratio of diatoxanthin (Dtx) to the sum of both pigments: (Dtx)/(Ddx+Dtx).

\section{Statistics}

Statistical analysis of physiological data was carried out by oneway analysis of variance (ANOVA) followed by a Holm-Sidak pair-wise comparison with the WT as control group using the program Sigma Plot 11.0 and a P-value $<0.05$ for the rejection of the null hypothesis.

\section{Results}

\section{Phylogenetic Analysis of Aureochromes}

In order to classify the four different aureochromes of $P$. tricornutum we performed phylogenetic analyses of aureochrome sequences presently available at NCBI and JGI genome databases. 32 putative aureochromes of twelve different organisms were identified by their conserved bZIP and LOV domain set-up and used for the generation of a maximum-likelihood phylogenetic tree using PhyML analyses (Figure 2). The aureochromes can be divided into four groups, which are characterized by group specific homologies especially between the bZIP and the LOV domain (Figure S1). Groups 1 and 2 are clearly distinct protein families corresponding to the two classes of aureochromes described for $V$. frigida [23]. Groups 3 and 4 are more related to each other but form distinct groups as indicated by a bootstrap value of 74 at the respective junction. Interestingly, in the given data set diatoms are the only organisms that feature group four aureochromes and the majority of group three aureochromes were found in diatoms as well. Remarkably, P. tricornutum possesses exactly one aureochrome per group and all investigated diatom genera feature both a class three and a class four aureochrome which further supports the distinction between the different groups. The two aureochromes of Chattonella marina var. antiqua and Aureococcus anophagefferens could not be assigned to any of the groups.

\section{Localisation of $P$. tricornutum Aureochromes}

As aureochromes are putative transcription factors possessing a bZIP domain, they might influence the physiology of the cells via gene regulation. A prerequisite for a protein to function as a nuclear transcription factor is an, at least temporary, nuclear location. We checked for putative nuclear localisation sequences (NLS) using the program NLStradamus [46] and found a high probability for a single NLS in each of the four $P$. tricornutum aureochromes (Figure S5). Generally, the aureochrome genes found in $P$. tricornutum apparently do not possess N-terminal targeting signals, even in cases of remaining uncertainty about the exact exon/intron boundaries or about the extend of open reading frames (Table $\mathrm{S} 2$ ). The only possible exception is AUREO1a. Here, the reading frame of the main gene model can be extended upstream to include a potential signal peptide according to prediction by SignalP 3.0 [47] (Table S2, see protein ID 56684). Hence, we also decided to study the localisation of the potential alternative gene product. We were not able to amplify the cDNA of AUREO1c (56742), possibly due to a low expression of this particular gene as indicated by a low number of EST sequences found in the JGI database. Accordingly, we have designed GFP fusion constructs for the EST supported full-length sequences of aureochromes la, $1 \mathrm{~b}$ and 2 and for the alternative version of AUREO1a featuring the putative signal peptide (laSig). To exclude the possibility that the C-terminal GFP domain might be translated via its original 
Table 1. Incident light intensities and cellular parameters.

\begin{tabular}{|c|c|c|c|c|c|c|c|}
\hline \multirow{2}{*}{$\begin{array}{l}\text { Parameter } \\
\text { Incident light intensity }\end{array}$} & \multicolumn{2}{|c|}{ Culture condition } & \multirow{2}{*}{$\begin{array}{l}\text { Wildtype } \\
24\end{array}$} & \multirow{2}{*}{$\begin{array}{l}\text { aureo1a-15 } \\
24\end{array}$} & \multirow{2}{*}{$\begin{array}{l}\text { aureo } 1 a-50 \\
24\end{array}$} & \multirow[t]{2}{*}{ aureo1a-15NT } & \multirow[t]{2}{*}{ aureo1a-50NT } \\
\hline & LL & BL & & & & & \\
\hline \multirow[t]{3}{*}[\mathrm{mol}\text{photons}\mathrm{m}^{-2}\mathrm{s}^{-1}]{} & & $\mathrm{RL}$ & 41 & 41 & 41 & & \\
\hline & $\mathrm{ML}$ & $\mathrm{BL}$ & 72 & 60 & 60 & & \\
\hline & & $\mathrm{RL}$ & 124 & 100 & 100 & & \\
\hline Chl a per cell & $\mathrm{LL}$ & BL & $0.65 \pm 0.04$ & $0.7 \pm 0.05$ & $0.51 \pm 0.07^{*}$ & $\mathrm{O}$ & - \\
\hline \multirow[t]{3}{*}{ [pg Chl $a$ cell $\left.^{-1}\right]$} & & RL & $0.56 \pm 0.06$ & $0.6 \pm 0.04$ & $0.52 \pm 0.08$ & 0 & $\mathrm{O}$ \\
\hline & $\mathrm{ML}$ & $\mathrm{BL}$ & $0.49 \pm 0.02$ & $0.29 \pm 0.03^{*}$ & $0.29 \pm 0.03^{*}$ & - & - \\
\hline & & RL & $0.46 \pm 0.04$ & $0.28 \pm 0.03^{*}$ & $0.30 \pm 0.03^{*}$ & - & - \\
\hline$a^{*}{ }_{\text {Phy }}$ & $\mathrm{LL}$ & $B L$ & $9.8 \pm 0.7$ & $10.3 \pm 0.1$ & $11.3 \pm 0.2^{*}$ & 0 & + \\
\hline \multirow[t]{3}{*}[\mathrm{m}^{2}(\mathrm{g}\mathrm{Chl}a)^{-1}]{} & & $\mathrm{RL}$ & $9.9 \pm 0.5$ & $9.8 \pm 0.2$ & $11.0 \pm 0.5^{*}$ & $\mathrm{O}$ & + \\
\hline & ML & $B L$ & $9.8 \pm 0.2$ & $12.0 \pm 0.2^{*}$ & $12.2 \pm 0.3^{*}$ & + & + \\
\hline & & $\mathrm{RL}$ & $9.9 \pm 0.3$ & $11.8 \pm 0.8^{*}$ & $11.9 \pm 0.5^{*}$ & + & + \\
\hline Dry weight & $\mathrm{LL}$ & $B L$ & $22.1 \pm 2.2$ & $27.6 \pm 1.6^{*}$ & $16.5 \pm 2.0^{*}$ & + & - \\
\hline \multirow[t]{3}{*}[\mathrm{pg}\text{cell}{}^{-1}]{} & & $\mathrm{RL}$ & $15.9 \pm 0.9$ & $19.5 \pm 1.2^{*}$ & $14.1 \pm 0.9^{*}$ & + & - \\
\hline & ML & $B L$ & $18.9 \pm 0.9$ & $14.3 \pm 1.4^{*}$ & $17.6 \pm 1.6$ & - & $\mathrm{O}$ \\
\hline & & $\mathrm{RL}$ & $18.5 \pm 1.7$ & $15.9 \pm 1.9^{*}$ & $14.3 \pm 1.4^{*}$ & - & - \\
\hline Growth rate & $\mathrm{LL}$ & $B \mathrm{~B}$ & $0.43 \pm 0.04$ & $0.42 \pm 0.08$ & $0.57 \pm 0.01^{*}$ & 0 & + \\
\hline \multirow[t]{3}{*}[\mu\mathrm{d}^{-1}]{} & & $\mathrm{RL}$ & $0.44 \pm 0.12$ & $0.46 \pm 0.06$ & $0.50 \pm 0.02$ & $\mathrm{O}$ & $\mathrm{O}$ \\
\hline & $\mathrm{ML}$ & $B L$ & $1.07 \pm 0.13$ & $1.00 \pm 0.06$ & $0.90 \pm 0.25$ & 0 & 0 \\
\hline & & RL & $0.74 \pm 0.08$ & $0.83 \pm 0.05$ & $0.94 \pm 0.14^{*}$ & $\mathrm{O}$ & + \\
\hline $1 / \Phi_{\mathrm{C}}$ & $\mathrm{LL}$ & BL & $14.3 \pm 2.4$ & $14.3 \pm 0.5$ & $12.5 \pm 0.7$ & 0 & 0 \\
\hline \multirow[t]{3}{*}[\mathrm{mol}\text{photons}(\mathrm{mol}\mathrm{C})^{-1}]{} & & $\mathrm{RL}$ & $13.8 \pm 0.7$ & $14.7 \pm 0.4$ & $15.2 \pm 1.3$ & $\mathrm{O}$ & 0 \\
\hline & ML & $B L$ & $13.4 \pm 0.1$ & $14.2 \pm 1.2$ & $12.4 \pm 0.8$ & $\mathrm{O}$ & $\mathrm{O}$ \\
\hline & & $\mathrm{RL}$ & $20.1 \pm 0.5$ & $14.7 \pm 1.5^{*}$ & $14.8 \pm 1.8^{*}$ & - & - \\
\hline
\end{tabular}

Aureo1a-15 and aureo1a-50 P. tricornutum cultures were grown under illumination with blue (BL) and red light (RL) under limiting light $\left(\mathrm{LL}\right.$, $\mathrm{Q}_{\mathrm{Phar}}=10 \mathrm{mmol}$ absorbed photons $\left.\mathrm{m}^{-2} \mathrm{~s}^{-1}\right)$ and medium light $\left(\mathrm{ML}, \mathrm{Q}_{\mathrm{phar}}=30 \mu \mathrm{mol}\right.$ absorbed photons $\left.\mathrm{m}^{-2} \mathrm{~s}^{-1}\right)$ conditions; corresponding WT data of Schellenberger Costa et al. [28] is included as reference. Chl $a$ per cell is given in pg cell ${ }^{-1}$, growth rate $(\mu)$ in $\mathrm{d}^{-1}, \mathrm{a}^{*}{ }_{\text {Phy }}$ : Chl $a$ specific absorption in $\mathrm{m}^{2} \mathrm{~g} \mathrm{Chl} a^{-1}$, dry weight is given in pg cell ${ }^{-1}$ and $1 / \Phi_{\mathrm{C}}$ : quantum requirement in mol absorbed photons mol fixed $C^{-1}$. Mean values are shown with standard deviation ( $n=3$ for $1 / \Phi_{C} n=5$ to 9 for other parameters). Mean values of aureo1a cultures marked with asterisks $\left(^{*}\right)$ are significantly different to the WT culture of the same culturing condition according to one-way ANOVA followed by Holm-Sidak pair wise comparison against WT as control group $(\mathrm{p}<0.05)$. O: no significant difference between WT and aureochrome 1a silenced strain; -: significant decrease in aureochrome 1a silenced strain compared to WT; +: significant increase in aureochrome 1a silenced strain compared to WT.

doi:10.1371/journal.pone.0074451.t001

ATG start codon, this codon was mutated to GGA and the transformed cell lines (marked by _ $\Delta \mathrm{ATG}$ ) were analysed as well. After biolistic transformation of wild type $P$. tricornutum using these constructs, we could not detect any difference in the location of AUREO:GFP and the corresponding AUREO:GFP_AATG fusion-proteins. Epifluorescence as well as laser scanning microscopy analysis of GFP expression together with Hoechst 33342 DNA staining revealed a clear nuclear location of all three investigated aureochromes (Figure 3 and Figure S2). AUREO1b and AUREO2 were exclusively located in the nucleus (demonstrated by the nuclear stain Hoechst 33342). The AUREOla fusion proteins showed a dominantly nuclear GFP fluorescence at all times, however, we also detected some weak GFP fluorescence in the cytosol (Figure 3 and Figures S2 and S6). Cell lines successfully transformed with any of the three AUREOla-GFP fusion constructs exhibited similar phenotypes with strong GFP fluorescence in the nucleus and weak fluorescence in the cytosol (Figure S6). This indicates that the N-terminal extension either does not serve as a signal peptide or that its signal peptide properties are weaker than the nuclear translocation signal.

\section{Screening of AUREO1a Deficient Cell Lines}

In order to understand the cellular roles of aureochromes in $P$. tricornutum, we investigated aureochrome knock-down cell lines. The most promising aureochrome for this investigation was AUREOla, because, in contrast to the other aureochromes, it is apparently located both in the nucleus and in the cytoplasm, suggesting a unique functional importance. The other investigated aureochromes are missing similar distinctive features and AUREO1b possesses a less conserved bZIP DNA binding domain (Figure S7). For confirmation of gene silencing, it is mandatory to follow the protein level of the silenced protein and for AUREOla an antiserum was available. An inducible vector containing an AUREO1a gene fragment cloned in sense and antisense orientation to facilitate gene silencing was generated following the method described by Lavaud et al. [48]. Transformed P. tricornutum cells were screened for reduced AUREOla protein content via immunoblotting of three independent replicates using the antiserum specific for AUREOla. The antiserum labelled two bands, one at $41.5 \mathrm{kDa}$, the expected size of AUREOla, and a clearly weaker band at about $47 \mathrm{kDa}$. The intensities of these two bands relative to each other were identical in all samples that were taken from cells grown under different conditions, indicating that the 


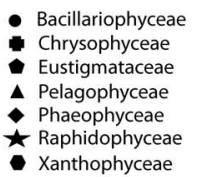
.
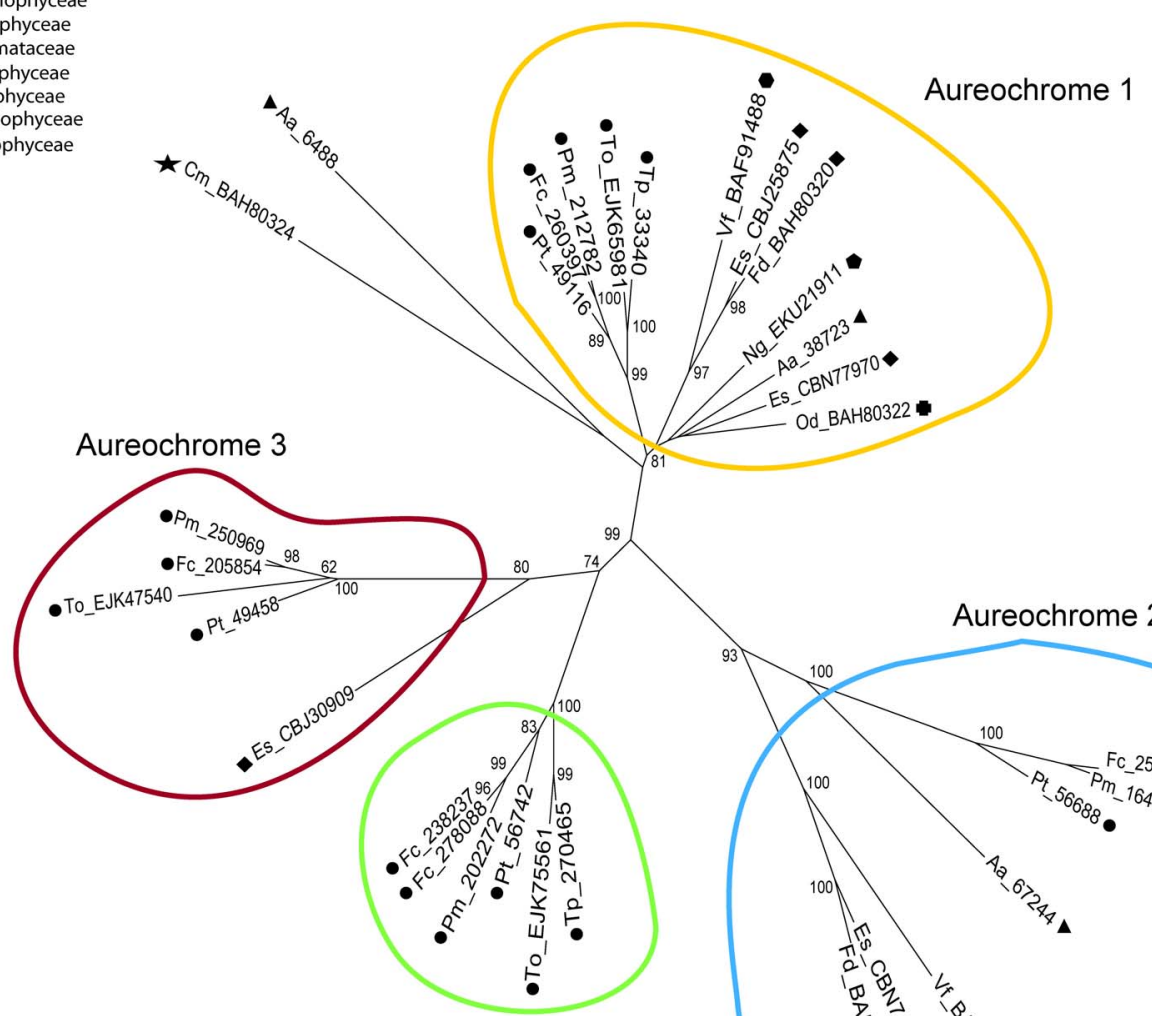

Aureochrome 4

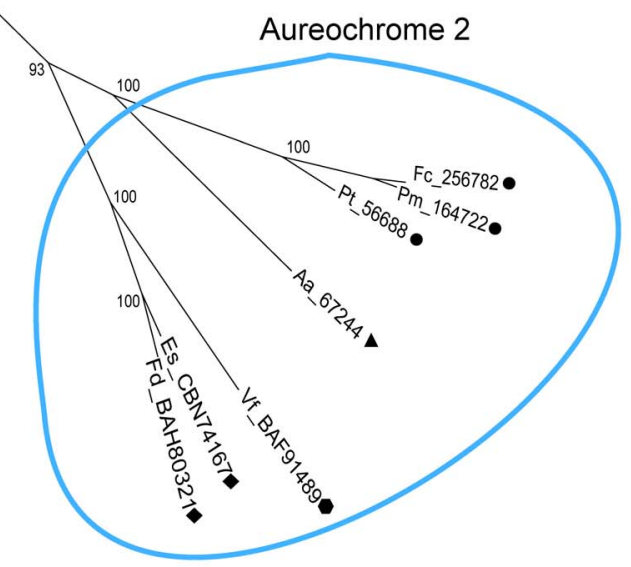

Figure 2. Phylogenetic analysis of putative aureochromes from different stramenopiles. The maximum likelihood tree was calculated using PhyML 3.0 [29] and incorporates 32 putative aureochrome sequences of twelve different stramenopiles identified by the unique bZIP/LOV domain setup. Numbers at nodes of subtrees correspond to bootstrap values greater than 45 . The accession numbers correspond either to Protein IDs (only digits) from the Joint Genome Institute database (JGl; http://www.jgi.doe.gov/) or to the accession numbers (two letters and digits) from the database of the National Center for Biotechnology Information (NCBl; http://www.ncbi.nlm.nih.gov/). Putative aureochromes of Phaeodactylum tricornutum (Pt), Fragilariopsis cylindrus CCMP $1102(\mathrm{Fc})$, Pseudo-nitzschia multiseries (Pm), Thalassiosira pseudonana (Tp), Thalassiosira oceanica $(\mathrm{To})$, Ectocarpus siliculosus (Es), Fucus distichus subsp. Evanescens ( $\mathrm{Fd})$, Aureococcus anophagefferens (Aa), Chattonella marina var. Antiqua (Cm), Ochromonas danica (Od), Nannochloropsis gaditana CCMP526 (Ng) and Vaucheria frigida (Vf) were taken into account. Four distinct groups of aureochromes could be identified highlighted by coloured markings. The different groups were designated aureochromes 1, 2, 3 and 4 with aureochromes 1 and 2 corresponding in homology to the aureochromes 1 and 2 of $V$. frigida [23], respectively.

doi:10.1371/journal.pone.0074451.g002

upper band represents a posttranslationally modified form of AUREO1a. In the strains aureo1a-15 and aureo1a-50, an obvious decrease of AUREOla protein levels was observed for cultures cultivated with nitrate as sole nitrogen source instead of ammonium (Figure 4A, corresponding loading controls are depicted in Figure 4B). This indicates a successful integration of the aureola silencing construct. As the construct is driven by an NR promoter we only observed AUREOla reduction in nitrate containing media. We furthermore could show that the nitrogen source has no influence on the amount of AUREOla protein in WT control cells. In both silenced strains, aureo1a-15 and aureo1a50, AUREOla levels of cultures grown with nitrate as sole nitrogen source were equally reduced to below $50 \%$ of the AUREOla content of cultures grown with ammonium as sole nitrogen source.

\section{Cellular Parameters}

To determine the role of AUREOla in the regulation of physiological processes, several cellular parameters of the aureochrome la silenced strains aureo1a-15 and aureo1a-50 were compared to WT cells. Under low light (LL) conditions, the Chl $a$ content per cell of aureo1a-15 was comparable to that of the corresponding WT culture whereas aureo1a-50 exhibited a slightly decreased Chl $a$ content per cell. Consequently, only aureo $1 a-50$ cultures showed a slightly increased $\mathrm{Chl} a$-specific in vivo absorption ( $\mathrm{a}^{*}$ Phy $)$ at LL conditions compared to WT cells (Table 1).

Differences between WT and aureochrome silenced strains were more pronounced at medium light (ML) conditions. Here, the Chl $a$ content per cell in both aureochrome la silenced strains was decreased to about $60 \%$ compared to the corresponding WT cultures grown at both light qualities. As a consequence, $\mathrm{a}^{*}$ Phy was increased by approximately $20 \%$ in both aureochrome la silenced strains under ML conditions (Table 1). The elevated $\mathrm{a}^{*}$ Phy of the aureochrome la silenced strains were taken into account for the adjustment of equal levels of $Q_{\text {Phar }}$ (see Methods section).

The comparison of cellular dry weight between WT cells and mutant strains did not yield in a consistent pattern. Compared to WT cells, the cellular dry weight of aureo 1a-50 was decreased at almost all culture conditions, whereas aureo $1 a-15$ cultures exhibited 


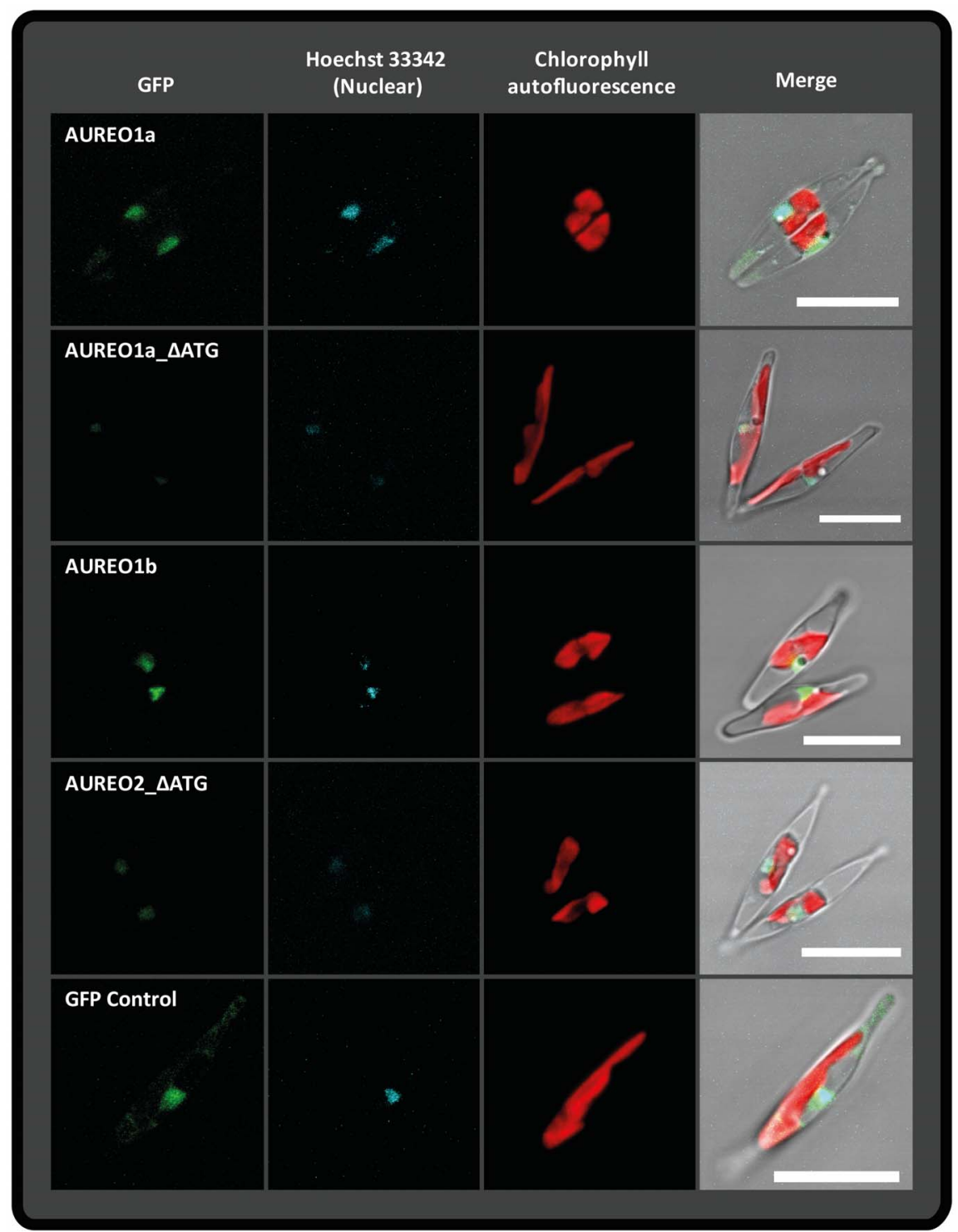

Figure 3. Localisation of GFP-fusion proteins of $P$. tricornutum aureochromes. Maximum intensity z-projections of LSM analyses are shown. From left to right: GFP fluorescence (green), nucleus staining Hoechst 33342 dye (cyan), chlorophyll autofluorescence (red) and a merge of all channels with a representative DIC single plane. The white scale bars correspond to $10 \mu \mathrm{m}$. All aureochromes feature a distinct nuclear localisation. AUREO1a fusion proteins often exhibit additional cytosolic signals (Figure S6), as can be seen here for AUREO1a. GFP_control is a transformed cell line of $P$. tricornutum featuring the enhanced GFP protein (GenBank Accession number AAB08060.1), which is missing any targeting sequence. It serves as reference for cytoplasmatic localisation. Here, the z-projections imply a co-localisation in the nucleus as well, but orthoview analysis of the LSM data revealed that the GFP fluorescence was only accumulating around the nucleus, while it co-localises in case of the aureochromes (Figure S2). doi:10.1371/journal.pone.0074451.g003

an increased cellular dry weight at LL conditions but a decreased cellular dry weight at ML conditions (Table 1).

At all culture conditions, the growth rates of aureo1a-15 cultures were comparable to those of WT cells (Table 1). Although growth rates were generally higher under ML compared to LL conditions for WT and aureo1a-15, this difference was more pronounced under BL (LL: $0.42 \mathrm{~d}^{-1}$; ML: $1.00 \mathrm{~d}^{-1}$ ) than under RL conditions (LL: $0.46 \mathrm{~d}^{-1}$; ML: $0.83 \mathrm{~d}^{-1}$ ). Compared to the WT cells, cultures of aureo1a-50 exhibited increased growth rates under LL conditions. Interestingly, under ML conditions similarly increased growth rates were detected for aureo1a-50 in comparison to WT cells only in combination with RL but not with BL. Thus, only aureo1a-50 exhibited a clearly different growth performance in comparison to WT cells.
The quantum requirement of carbon fixed in the biomass (1/ $\left.\Phi_{\mathrm{C}}\right)$ is the most integrating growth parameter since it incorporates all energetic losses of the cellular metabolism. Despite the differences of cellular Chl $a$ content and cellular dry weight between WT cells and aureochrome la silenced strains, $1 / \Phi_{\mathrm{C}}$ exhibited a comparable pattern to the growth rates. No significant differences between WT cultures and cultures of both aureochrome la silenced strains were observed in BL irrespective of LL or ML conditions (Table 1). Under these conditions quantum efficiency varied only slightly between $12.5 \pm 0.7$ and $15.2 \pm 1.3 \mathrm{~mol}$ absorbed photons mol per fixed C. Interestingly, the clear increase in quantum requirement of WT cells under ML RL conditions was not observed for both aureochrome la silenced strains. 

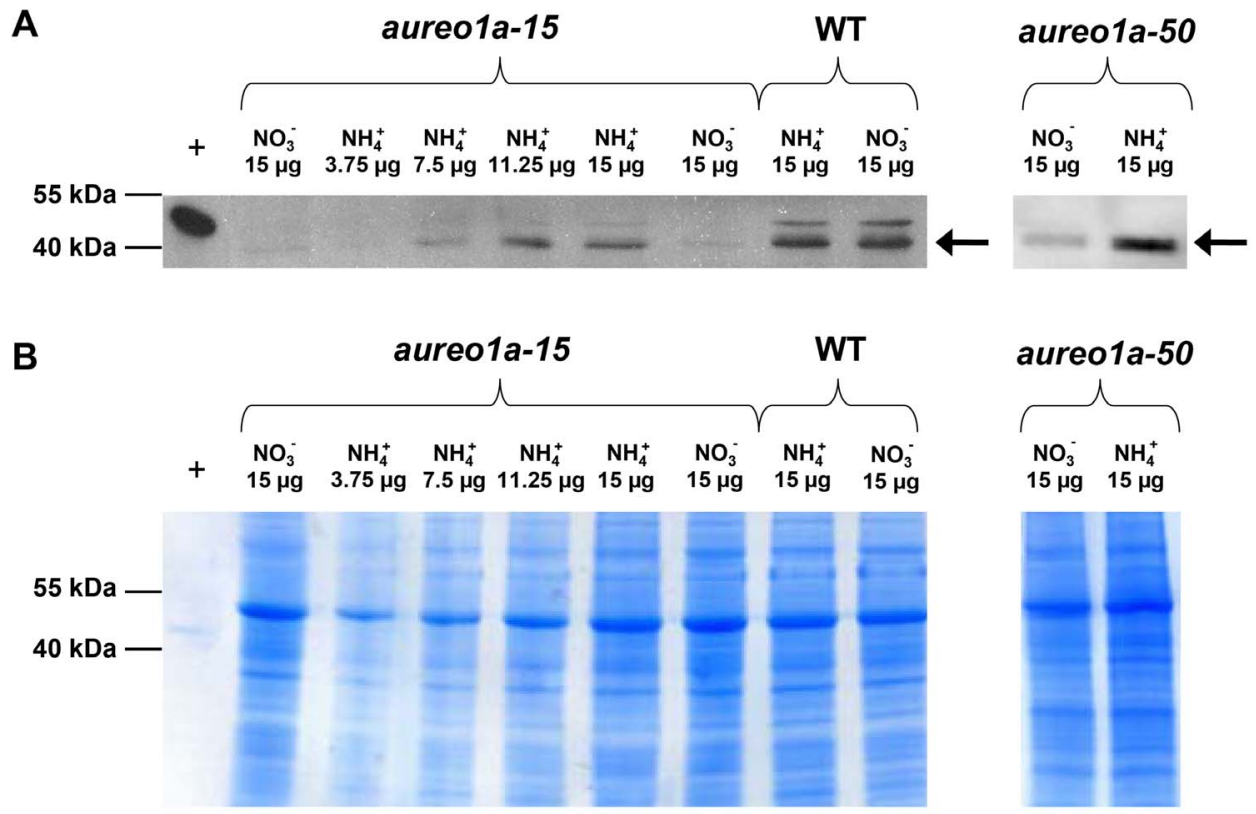

Figure 4. A) Exemplary relative quantification of AUREO1a concentration in protein extracts of $P$. tricornutum WT, aureo1a-15 and aureo $1 a-50$ by an immunoblot using an antiserum specific for $P$. tricornutum AUREO1a. Cultures were grown with either nitrate or ammonium as sole nitrogen source. Nitrate activates the promoter of the applied silencing construct resulting in a decreased amount of AUREO1a protein. Several dilutions of the protein extract of the ammonium grown aureo1a-15 culture were loaded on the gel in order to assess the efficiency of AUREO1 a downregulation. Two co-regulated bands are visible, one at the expected size of AUREO1a, 41.5 kDa (indicated by arrows), and a weaker band at about $47 \mathrm{kDa}$, which possibly reflects a post-translational modification of the protein. B) Loading control of protein extracts used for immunoblotting. The gels used for immunoblotting and as loading control were loaded with identical amounts of protein. The proteins of the loading control gels were stained with colloidal Coomassie. +: Purified heterologously expressed AUREO1a with His-tag. doi:10.1371/journal.pone.0074451.g004

\section{Photosynthesis Rates}

When cultivated at LL BL, both aureochrome la silenced strains exhibited significantly increased photosynthesis rates compared to WT cells with maximum photosynthesis rates $\left(\mathrm{P}_{\mathrm{Max}}\right)$ of about $240 \mu \mathrm{mol} \mathrm{O} \mathrm{O}_{2} \mathrm{mg} \mathrm{Chl} \mathrm{a}{ }^{-1} \mathrm{~h}^{-1}$ (aureola) compared to $196 \mu \mathrm{mol} \mathrm{O} \mathrm{mg} \mathrm{Chl} \mathrm{a}^{-1} \mathrm{~h}^{-1}$ (WT; Figure 5A). At LL RL only aureo1a-15 exhibited a significantly increased $\mathrm{P}_{\mathrm{Max}}$ in comparison to WT cultures (Figure 5B).

Cultivation at ML BL resulted in remarkably high photosynthesis rates with a $\mathrm{P}_{\mathrm{Max}}$ of $382 \mu \mathrm{mol} \mathrm{O} \mathrm{O}_{2} \mathrm{mg} \mathrm{Chl} \mathrm{a}{ }^{-1} \mathrm{~h}^{-1}$ for aureo1a-15 and $332 \mu \mathrm{mol} \mathrm{O}_{2} \mathrm{mg} \mathrm{Chl} \mathrm{a} \mathrm{a}^{-1} \mathrm{~h}^{-1}$ for aureo1a-50. These rates were significantly higher than the $\mathrm{P}_{\text {Max }}$ of the corresponding WT culture $\left(243 \mu \mathrm{mol} \mathrm{O}_{2} \mathrm{mg} \quad \mathrm{Chl} \mathrm{a}^{-1} \mathrm{~h}^{-1}\right.$; Figure $5 \mathrm{C}$ ). A comparable pattern was observed under ML RL. The $\mathrm{P}_{\text {Max }}$ values of both aureochrome la silenced strains (about $265 \mu \mathrm{mol} \mathrm{O}_{2} \mathrm{mg} \mathrm{Chl} \mathrm{a} \mathrm{a}^{-1} \mathrm{~h}^{-1}$ ) were significantly increased compared to $\mathrm{P}_{\mathrm{Max}}$ of corresponding WT culture $\left(205 \mu \mathrm{mol} \mathrm{O}_{2}\right.$ $\mathrm{mg} \mathrm{Chl} \mathrm{a}{ }^{-1} \mathrm{~h}^{-1}$, Figure 5D). Hence, the aureo 1 a cultures exhibited a high light acclimation status clearly exceeding that of WT cultures grown under identical conditions. Interestingly, the trend of increased photosynthesis rates under ML in comparison to LL conditions was observed for both BL and RL aureochrome la silenced cultures, albeit more pronounced under BL conditions. In contrast, in WT cells this effect was only detected under BL conditions.

\section{Non-photochemical Quenching and XC Pigment Pool Size}

In parallel to the measurement of light response curves, fluorescence parameters were recorded which, in combination with excess illumination experiments, were used to evaluate the capacity of NPQ and the $\mathrm{XC}$ pigment pool size of aureo1 a strains in comparison to the WT cells. WT cells of $P$. tricornutum show a significantly higher NPQ capacity after cultivation under illumination with $\mathrm{BL}$ as compared to illumination with RL, irrespective of LL or ML conditions [28]. Under LL conditions this pattern was also observed in both aureochrome la silenced strains with only slightly increased NPQ compared to WT cells (Figure 6A \& B). However, under ML conditions significantly increased maximal NPQ values were observed in both aureochrome la silenced strains in comparison to WT cells irrespective of the light quality (Figure 6C \& D). The highest NPQ values of the aureo $1 a$ strains at ML were higher than the respective values at LL for both $\mathrm{BL}$ and RL cultures (compare Figure 6A \& $\mathrm{C}$ and Figure 6B \& D). In contrast, there was no change in maximum NPQ between LL or ML conditions in the WT cells.

For both aureochrome la silenced strains significantly higher diadinoxanthin $(\mathrm{Ddx})$ concentrations were found in comparison to WT cells at almost all growth conditions. It is noteworthy that the Ddx content was usually higher in aureo1a-15 than in aureo1a-50 (Table 2). Moreover, in WT cells the Ddx concentration was only increased comparing ML to LL under BL conditions but not under RL conditions. In contrast, aureo1a strains exhibited increased Ddx concentrations in all ML conditions compared to the corresponding LL.

Table 2 presents de-epoxidation states (DES) of XC pigments which were determined after a $10 \mathrm{~min}$ period of illumination with $1000 \mu \mathrm{mol}$ photons $\mathrm{m}^{-2} \mathrm{~s}^{-1}$. The DES is depicted as the ratio of diatoxanthin (Dtx) per (Ddx+Dtx). Generally, an elevated DES was observed in WT cells and aureo1a strains under BL conditions compared to RL conditions. No differences of the DES could be detected in WT cells to both aureochrome la silenced strains under BL conditions. However, under RL conditions the DES 


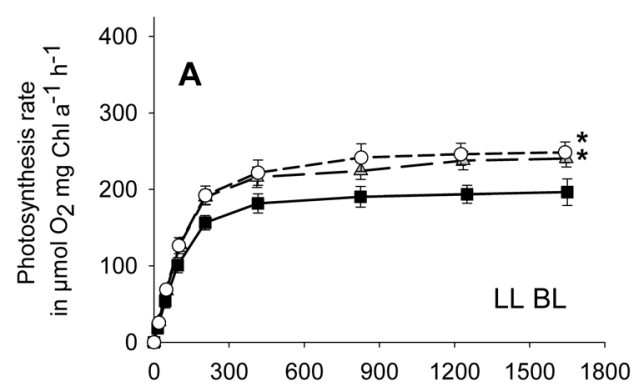

B
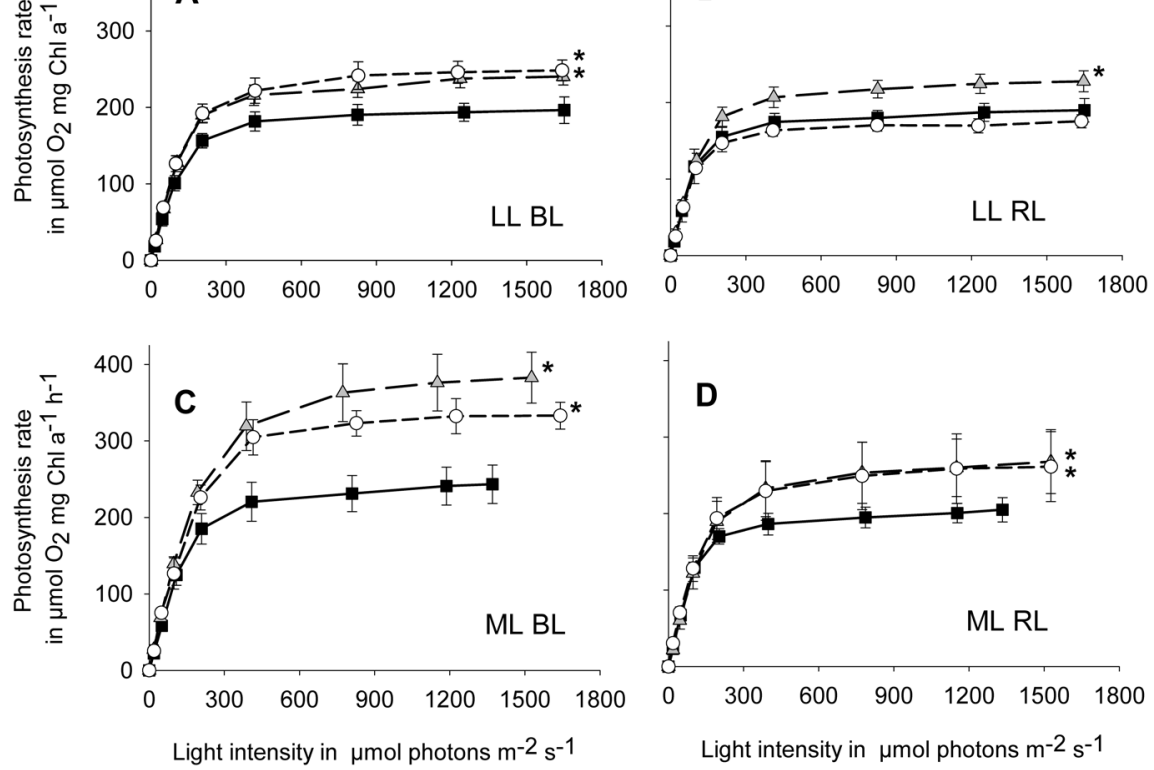

Figure 5. Photosynthesis rates of aureo1a-15 (grey triangles) and aureo1a-50 (white circles) $P$. tricornutum cultures depending on the incident light intensity in the measuring cuvette; corresponding WT data of Schellenberger Costa et al. [28] (black squares) are included for better comparison. Algae were cultivated at a $Q_{\text {phar }}$ of $10 \mu \mathrm{mol}$ absorbed photons $\mathrm{m}^{-2} \mathrm{~s}^{-1}$ (LL) under illumination with blue (A) and red light (B) and further at a $Q_{\text {phar }}$ of $30 \mu \mathrm{mol}$ absorbed photons $\mathrm{m}^{-2} \mathrm{~s}^{-1}$ (ML) under illumination with blue (C) and red light (D). Mean values are shown with standard deviation $(n=9)$. Maximum photosynthesis rates of each culture condition were tested for the occurrence of significant differences between WT and aureochrome 1a silenced strains using a one-way ANOVA followed by a Holms-Sidak pair-wise comparison test with the WT as control group. Significant differences are marked with asterisks $(p<0.05)$.

doi:10.1371/journal.pone.0074451.g005

values were always significantly higher in the aureochrome la silenced strains. Interestingly, this resulted in the observation that in aureo1a-15 the DES after excess light illumination was comparable for ML RL and ML BL cultures. The highest DES was measured in aureo1a-50 cultures cultivated under ML BL. In summary, cultures of aureochrome la silenced strains tended to exhibit an increased high light acclimation status compared to the corresponding WT cultures concerning NPQ capacity, Ddx concentration and Ddx de-epoxidation.

\section{Discussion}

High light acclimation in diatoms is typically associated with a decrease of the cellular Chl $a$ content and enhanced maximum photosynthesis rates. Furthermore, the photoprotective potential is clearly increased which is usually accompanied by an increased pool size of xanthophyll cycle pigments and an accelerated deepoxidation of $\mathrm{Ddx}$ to Dtx under excess light conditions $[28,49,50,51,52]$. High light acclimation is further connected to the up- or down-regulation of the expression of specific genes involved in photoprotection or light harvesting $[53,54,55,56]$ as well as other processes such as the carbon metabolism [54]. Similar to high light acclimation, also the re-acclimation to illumination after prolonged darkness is accompanied by extensive transcriptional changes [57]. In a previous study we have shown that RL is not a trigger for light acclimation in WT cells of $P$. tricornutum and that the formation of an apparently high light acclimated phenotype is mediated by the absorption of BL despite moderate light intensities at cultivation [28]. Based on these results it was suggested that aureochromes might play an important role in the process of BL perception and that the active form of one or more of the aureochromes might act as transcription factors and induce or enhance the acclimation to higher light intensities. The predicted nuclear localisation of all four aureochromes and the confirmation by successful GFP fusion experiments for three of them further support a role of the aureochromes as transcription factors. Interestingly, AUREOla was detected both in the nucleus and in the cytoplasm, indicating a different functionality compared to the other aureochromes, possibly involving shuttling between cytoplasm and nucleus.

To study the influence of AUREOla on the photoacclimation of $P$. tricornutum, we cultivated the aureochrome la silenced strains at BL and RL of different light intensities. Surprisingly, the results suggest a regulation of BL mediated light acclimation which stands in clear contrast to our expectations. At LL conditions, WT cells and the aureochrome la silenced strains showed very similar physiological properties under illumination with both BL and RL. This indicates that AUREOla is not of major importance for the photoacclimation of P. tricornutum at low light intensities. Instead, the observed differences between the BL and RL acclimated phenotypes of the WT might be mediated by other BL receptors like other aureochromes or members of the cryptochrome family.

At ML conditions, the physiological response of AUREOla silencing cell lines showed explicit characteristics of acclimation to increased light intensities irrespectively of the applied light quality, including a reduction of the cellular Chl $a$ content and the cellular dry weight as well as increased photosynthesis rates and an enhanced photoprotective potential. Hence, it can be stated that aureochrome la silenced cultures were 'hyper' acclimated under ML illumination suggesting that AUREOla is involved in the photoacclimation of $P$. tricornutum. Considering the lacking influence of AUREOla on the phenotype of LL cultures, this indicates the presence of a light intensity perception mechanism 

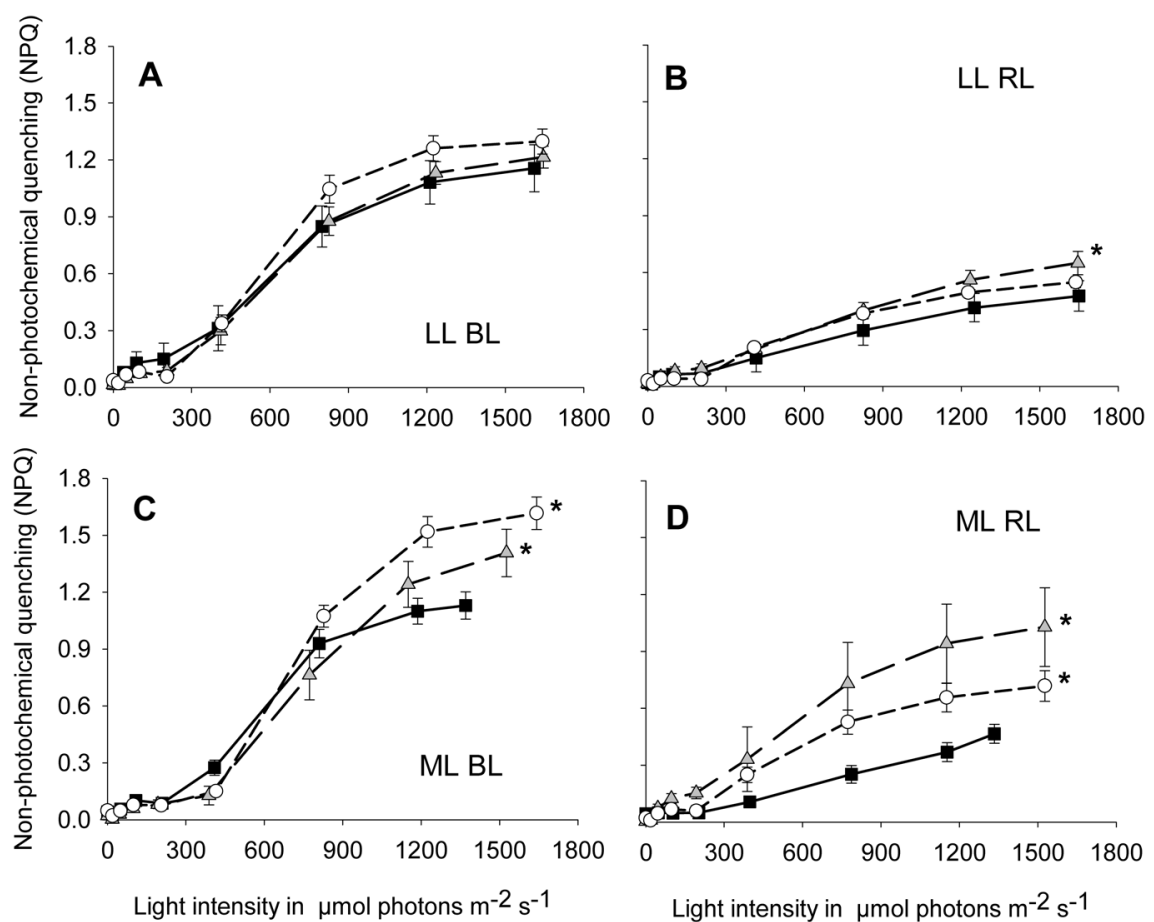

Figure 6. Non-photochemical quenching (NPQ) of aureo1a-15 (grey triangles) and aureo1a-50 (white circles) $P$. tricornutum cultures depending on the incident light intensity in the measuring cuvette; corresponding WT data of Schellenberger Costa et al. [28] (black squares) are included for better comparison. Algae were cultivated at a Qphar of $10 \mu \mathrm{mol}$ absorbed photons $\mathrm{m}^{-2} \mathrm{~s}^{-1}$ (LL) under illumination with blue (A) and red light (B) and further at a $Q_{\text {Phar }}$ of $30 \mu$ mol absorbed photons $\mathrm{m}^{-2} \mathrm{~s}^{-1}(\mathrm{ML})$ under illumination with blue (C) and red light (D). Mean values are shown with standard deviation $(n=9)$. The maximum NPQ of each culture condition was tested for the occurrence of significant differences between WT and aureochrome 1a silenced using a one-way ANOVA followed by a Holms-Sidak pair-wise comparison test with the WT as control group. Significant differences are marked with asterisks $(p<0.05)$.

doi:10.1371/journal.pone.0074451.g006

which is negatively affected by aureochrome la and which may comprise the reduction states of stromal compounds or the reduction state of the PQ pool. This would correspond to the recent observation that the nuclear gene expression is influenced by the addition of inhibitors of the linear electron transport in $P$. tricornutum [56].
Unexpectedly, aureo1a cultures showed different characteristics compared to WT cells also under ML RL conditions. The physiological parameters of the aureo1a cultures clearly showed signs of an acclimation to increased light intensities whereas WT cells showed no corresponding acclimation at ML RL conditions in comparison to LL RL conditions. Hence, in aureochrome la silenced strains RL was able to trigger a limited acclimation to

Table 2. Diadinoxanthin (Ddx) concentration and de-epoxidation state (DES).

\begin{tabular}{|c|c|c|c|c|c|c|c|}
\hline \multirow{2}{*}{$\begin{array}{l}\text { Parameter } \\
\text { Ddx under culture }\end{array}$} & \multicolumn{2}{|c|}{ Culture condition } & \multirow{2}{*}{$\begin{array}{l}\text { Wildtype } \\
110 \pm 4\end{array}$} & \multirow{2}{*}{$\frac{\text { aureo } 1 a-15}{125 \pm 7^{*}}$} & \multirow{2}{*}{$\frac{\text { aureo1a-50 }}{119 \pm 6^{*}}$} & \multirow{2}{*}{$\begin{array}{l}\text { aureo1a-15NT } \\
+\end{array}$} & \multirow{2}{*}{$\begin{array}{l}\text { aureo1a-50N1 } \\
+\end{array}$} \\
\hline & $\mathrm{LL}$ & $\mathrm{BL}$ & & & & & \\
\hline conditions & & $\mathrm{RL}$ & $82 \pm 4$ & $90 \pm 4^{*}$ & $89 \pm 2 *$ & + & + \\
\hline \multirow[t]{2}{*}[\mathrm{mmol}(\mathrm{mol}\mathrm{Chl}\mathrm{a})^{-1}]{} & $\mathrm{ML}$ & $\mathrm{BL}$ & $130 \pm 20$ & $165 \pm 13^{*}$ & $145 \pm 11$ & + & $\mathrm{O}$ \\
\hline & & $\mathrm{RL}$ & $83 \pm 3$ & $134 \pm 22^{*}$ & $106 \pm 15^{*}$ & + & + \\
\hline DES after illumination & $\mathrm{LL}$ & $\mathrm{BL}$ & $0.38 \pm 0.01$ & $0.40 \pm 0.03$ & $0.40 \pm 0.01$ & 0 & 0 \\
\hline with excess light & & $\mathrm{RL}$ & $0.26 \pm 0.01$ & $0.30 \pm 0.01 *$ & $0.28 \pm 0.01^{*}$ & + & + \\
\hline \multirow[t]{2}{*}{ [r.U.] } & $\mathrm{ML}$ & $\mathrm{BL}$ & $0.45 \pm 0.01$ & $0.43 \pm 0.04$ & $0.48 \pm 0.02$ & $\mathrm{O}$ & 0 \\
\hline & & $\mathrm{RL}$ & $0.29 \pm 0.02$ & $0.44 \pm 0.03^{*}$ & $0.42 \pm 0.05^{*}$ & + & + \\
\hline
\end{tabular}

Aureo1a-15 and aureo1a-50 P. tricornutum cultures were grown under illumination with blue (BL) and red light (RL) under limiting light (LL, $Q_{\text {phar }}=10 \mu$ mol absorbed photons $\mathrm{m}^{-2} \mathrm{~s}^{-1}$ ) and medium light (ML, Q Q phar $=10 \mu \mathrm{mol}$ absorbed photons $\mathrm{m}^{-2} \mathrm{~s}^{-1}$ ) conditions; corresponding WT data of Schellenberger Costa et al. [28] is included as reference. Ddx-concentration is given in $\mathrm{mmol} \mathrm{mol} \mathrm{Chl} a^{-1}$. DES was measured after $10 \mathrm{~min}$ of illumination with $1000 \mu \mathrm{mol}$ photons $\mathrm{m}^{-2} \mathrm{~s}^{-1}$ as the ratio of diatoxanthin (Dtx) to $D d x+D$ tx. Mean values are shown with standard deviation $\left(n=5\right.$ to 9 ). Mean values of aureo 1a cultures marked with asterisks $\left(^{*}\right)$ are significantly different to the WT culture of the same culturing condition according to one-way ANOVA followed by Holm-Sidak pair wise comparison against WT as control group $(p<0.05)$. O: no significant difference between WT and aureochrome 1a silenced strain; -: significant decrease in aureochrome 1a silenced strain compared to WT; +: significant increase in aureochrome 1a silenced strain compared to WT.

doi:10.1371/journal.pone.0074451.t002 
increased light intensities. A possible explanation for these results could be that AUREOla does not induce or enhance high light acclimation but, to the contrary, acts as a repressor of the formation of a phenotype which is acclimated to higher light intensities. Furthermore, it can be deduced that the RL acclimated state of WT cells is not simply the consequence of missing BL absorption, but represents a discrete acclimation state which requires the presence of AUREOla. The involvement of BL photoreceptors in the generation of RL phenotypes is not unusual. For example, it was demonstrated that the neutral radical state of an animal-like cryptochrome of Chlamydomonas reinhardtii is able to absorb both BL and RL [58]. However, the biochemical properties of the AUREOla LOV-domain do not allow the generation of a radical state of the chromophore which would be required for RL absorption. Accordingly, the absorption of the AUREOla of $P$. tricornutum was shown to be restricted to wavelengths in the blue range ([26] and T. Kottke, personal communication).

Therefore, other interaction mechanisms between AUREOla and RL perception pathways have to be assumed. Recently, protein complexes containing RL absorbing phytochromes and BL absorbing phototropins were discovered in the plasma membranes of Physcomitrella patens and Arabidopsis thaliana [59]. These protein complexes were shown to be essential for full functionality of phytochromes explaining the loss of RL induced chloroplast movement in phototropin deficient strains of $P$. patens described earlier [60]. Due to the absence of phototropin photoreceptors in diatoms, it can be speculated that AUREOla may functionally substitute phototropin as interaction partner of phytochrome. This would make AUREOla essential for a correct function of phytochromes and thus, for RL induced signalling in $P$. tricomutum. The observed additional cytosolic localisation of AUREOla would in principle allow an interaction with plasma membrane bound phytochromes.

In addition to the physical interaction of phototropins and phytochromes, various other interaction mechanisms between BL and RL perception pathways were described for higher plants and for green algae. For example, it was shown that both phytochromes and cryptochromes regulate the expression of certain components of the phototropin signalling pathway $[61,62,63]$ or alter their cellular location [64]. Furthermore, the protein phytochrome kinase substrate 4 was shown to be substrate of both phytochromes and phototropins [65]. If indeed an interaction between AUREOla and a phytochrome would occur in $P$. tricornutum, the phenotype of aureo1a and WT cultures should change upon adding far red radiation to either BL or RL conditions, respectively. An interaction between AUREOla and a RL perception pathway could be involved in the perception of the $\mathrm{BL} / \mathrm{RL}$ ratio. This ratio may vary enormously in the euphotic zones of the natural habitats of diatoms [5] and it was shown to correlate comparatively well with the ambient light intensity $[6,66]$. Therefore, a putative interaction between AUREOla and a RL perception pathway might enable the diatoms to combine sensing of light qualities with the ability to integrate the perceived light intensities into a total light intensity perception allowing the cells to acclimate better to their environment. Alternatively, it is possible that the altered phenotypes of the transformed cell lines under both BL and RL conditions result from a light-independent functionality of AUREOla. However, there is convincing evidence that AUREOla acts as BL activated transcription factor for the dsCYC2 gene in P. tricornutum [27]. Furthermore, AUREOla LOV $\alpha$ reacts with conformational changes in response to BL exposure allowing homodimerisation and enhanced DNA binding [26]. Thus it seems likely that the observed light dependent physiological effects originate primarily from a BL induced functionality of AUREOla.

One important feature of our work is the finding that, although four different aureochromes are expressed in P. tricornutum, the silencing of a single aureochrome gene cannot be compensated. This indicates that the individual aureochromes might have discrete functions similar to the AUREOl and 2 proteins of $V$. frigida [23]. This is further supported by the observation of differential circadian gene expression patterns of the aureochromes of Thalassiosira pseudonana [67] and by our finding of four distinct groups of aureochromes thar feature group specific homologous regions. Group 1 and 2 correspond to the respective aureochromes of $V$. frigida described by Takahashi et al. [23], while the other two groups 3 and 4 are dominated by diatom aureochromes, raising the question whether diatoms might possess exclusive classes of aureochromes associated with diatom specific functions. This notion is also supported by the observation that $P$. tricormutum, like the diatoms $P$. multiseries and $F$. cylindrus, possesses at least one aureochrome of each group. If this pattern is confirmed in future research, a re-evaluation of the current aureochrome nomenclature might be appropriate.

A preceding study on the physiological characterisation of $P$. tricornutum in response to different light qualities [28] revealed that the quantum requirement of biomass production was significantly increased in WT cells under ML RL conditions compared to all other tested culture conditions. Although monochromatic RL conditions are artificial and do not occur naturally, this demonstrated that chromatic acclimation can affect the overall cellular energy balance. In contrast to WT cultures, an increased quantum requirement under $\mathrm{ML}$ RL conditions compared to other applied culturing conditions was not detected in aureo 1 a cultures. This is in agreement with the apparent acclimation of the aureochrome la silenced strains to increased light intensities at ML RL conditions as indicated by elevated NPQ capacity, $\mathrm{P}_{\max }$ or xanthophyll cycle pigment concentrations. Generally, no obvious disadvantage of aureola cultures compared to WT cells was detected using our specific experimental setup with persistent exponential growth. However, WT and aureo1a cultures were additionally grown in batch cultures revealing that aureochrome la silenced strains show a prolonged lag phase during batch cultivation compared to WT cultures, while no significant differences of growth rates during the exponential growth phase were detected (Experiment S1). This indicates that the suppression of AUREOla in P. tricornutum disturbs the initial photoacclimation after changes of the ambient light conditions rather than the growth performance under steady state conditions. Thus, one role of AUREOla could be the promotion of acclimation to fast changes of ambient light conditions, which are common in the natural habitat of diatoms [5]. In this context it would be interesting to study the performance of aureola cultures under fluctuating light conditions.

\section{Supporting Information}

Figure S1 Alignment of 32 aureochromes of twelve different stramenopiles which was used for the generation of a phylogenetic tree by PhyML calculation. (PDF)

Figure S2 Orthoview confocal laser scanning microscopy pictures for visualisation of nuclear co-localisation of aureochrome fusion proteins.

(PDF) 
Figure S3 Sequence of the synthetic gene used for RNAiconstruct generation.

(PDF)

Figure S4 Vector map of modified pPha-NR used as scaffold for silencing construct generation.

(PDF)

Figure S5 Nuclear localisation sequence (NLS) prediction by the NLStradamus application of the four Phaeodactylum tricornutum aureochromes.

(PDF)

Figure S6 Epifluorescence microscopy images of different aureochrome 1a-GFP fusion proteins to visualise dual localisation in nucleus and cytosol.

(PDF)

Figure S7 bZIP and LOV domain conservation in $P$. tricornutum aureochromes.

(PDF)

Table S1 Primers used for amplification of aureochromes from $P$. tricornutum cDNA and verification and sequencing of the aureochrome silencing transformants.

(PDF)

\section{References}

1. Geider RJ, Delucia EH, Falkowski PG, Finzi AC, Grime JP et al. (2001) Primary productivity of planet earth: biological determinants and physical constraints in terrestrial and aquatic habitats. Global Change Biology 7(8): 849-882.

2. Nelson DM, Treguer P, Brzezinski MA, Leynaert A, Queguiner B (1995) Production and dissolution of biogenic silica in the ocean - revised global estimates, comparison with regional data and relationship to biogenic sedimentation. Glob Biogeochem Cycle 9(3): 359-372.

3. Armbrust EV (2009) The life of diatoms in the world's oceans. Nature 459(7244): 185-192.

4. MacIntyre HL, Kana TM, Geider RJ (2000) The effect of water motion on short-term rates of photosynthesis by marine phytoplankton. Trends in Plant Science 5(1): 12-17.

5. Kirk JTO (2011) Light \& photosynthesis in aquatic ecosystems. Cambridge: Cambridge University Press.

6. Ragni M, D'Alcala MR (2004) Light as an information carrier underwater. Journal of Plankton Research 26(4): 433-443.

7. Brunet C, Lavaud J (2010) Can the xanthophyll cycle help extract the essence of the microalgal functional response to a variable light environment? Journal of Plankton Research 32(12): 1609-1617.

8. Lavaud J, Strzepek RF, Kroth PG (2007) Photoprotection capacity differs among diatoms: Possible consequences on the spatial distribution of diatoms related to fluctuations in the underwater light climate. Limnology and Oceanography 52(3): 1188-1194.

9. Ruban AV, Lavaud J, Rousseau B, Guglielmi G, Horton P et al. (2004) The super-excess energy dissipation in diatom algae: comparative analysis with higher plants. Photosynthesis Research 82(2): 165-175.

10. Depauw FA, Rogato A, d'Alcala MR, Falciatore A (2012) Exploring the molecular basis of responses to light in marine diatoms. Journal of Experimental Botany 63(4): 1575-1591.

11. Margalef R (1978) Life-forms of phytoplankton as survival alternatives in an unstable environment. Oceanol Acta 1(4): 493-509.

12. Goss R, Jakob T (2010) Regulation and function of xanthophyll cycle-dependent photoprotection in algae. Photosynthesis Research 106(1-2): 103-122.

13. Apt KE, Kroth-Pancic PG, Grossman AR (1996) Stable nuclear transformation of the diatom Phaeodactylum tricornutum. Molecular \& General Genetics 252(5): $572-579$.

14. Armbrust EV, Berges JA, Bowler C, Green BR, Martinez D et al. (2004) The genome of the diatom Thalassiosira pseudonana: Ecology, evolution, and metabolism. Science 306(5693): 79-86.

15. Bowler C, Allen AE, Badger JH, Grimwood J, Jabbari K et al. (2008) The Phaeodactylum genome reveals the evolutionary history of diatom genomes. Nature 456(7219): 239-244

16. Bräutigam K, Dietzel L, Pfannschmidt T (2010) Hypothesis: A binary redox control mode as universal regulator of photosynthetic light acclimation. Plant signaling \& behavior 5(1): 81-85.

17. Durnford DG, Falkowski PG (1997) Chloroplast redox regulation of nuclear gene transcription during photoacclimation. Photosynthesis Research 53(2-3): 229-241.
Table S2 Comparison of Phaeodactylum tricornutum aureochrome gene models.

$(\mathrm{PDF})$

Experiment S1 Growth curves of WT, aureo1a-15 and aureo1a-50 batch cultures grown under different light conditions.

(PDF)

\section{Acknowledgments}

We thank D. Ewe and C. Kolb for their help on designing the core silencing vector and modifying the shuttle vector pPha-NR correspondingly, A. Schober and P. Voss for their assistance in the cloning of the constructs, D. Ballert for her help in biolistic transformation, A. Eckert for her help in screening the transformed cell lines, E. Herman and T. Kottke for kindly providing purified heterologously expressed AUREOla protein and the Universität Konstanz BioImaging Center (BIC) for access to the confocal laser scanning microscope.

\section{Author Contributions}

Conceived and designed the experiments: BSC MS AJ AG TJ PGK CW. Performed the experiments: MS AJ GRB AG. Analyzed the data: BSC MS AJ AG TJ PGK CW. Wrote the paper: BSC CRB TJ MS PGK CW.

18. Foyer CH, Neukermans J, Queval G, Noctor G, Harbinson J (2012) Photosynthetic control of electron transport and the regulation of gene expression. Journal of Experimental Botany 63(4): 1637-1661.

19. Bräutigam K, Dietzel L, Kleine T, Stroeher E, Wormuth D et al. (2009) Dynamic plastid redox signals integrate gene expression and metabolism to induce distinct metabolic states in photosynthetic acclimation in Arabidopsis. Plant Cell 21(9): 2715-2732

20. Li Z, Wakao S, Fischer BB, Niyogi KK (2009) Sensing and responding to excess light. Annual Review of Plant Biology. 239-260.

21. Walters RG, Rogers JJM, Shephard F, Horton P (1999) Acclimation of Arabidopsis thaliana to the light environment: the role of photoreceptors. Planta 209(4): 517-527.

22. Coesel S, Mangogna M, Ishikawa T, Heijde M, Rogato A et al. (2009) Diatom PtCPF1 is a new cryptochrome/photolyase family member with DNA repair and transcription regulation activity. Embo Reports 10(6): 655-661.

23. Takahashi F, Yamagata D, Ishikawa M, Fukamatsu Y, Ogura Y et al. (2007) AUREOCHROME, a photoreceptor required for photomorphogenesis in stramenopiles. Proceedings of the National Academy of Sciences of the United States of America 104(49): 19625-19630.

24. Suetsugu N, Wada M (2013) Evolution of three LOV blue light receptor families in green plants and photosynthetic stramenopiles: Phototropin, ZTL/FKF1/ LKP2 and Aureochrome. Plant \& cell physiology 54(1): 8-23.

25. Ishikawa M, Takahashi F, Nozaki H, Nagasato C, Motomura T et al. (2009) Distribution and phylogeny of the blue light receptors aureochromes in eukaryotes. Planta (Berlin) 230(3): 543-552.

26. Herman E, Sachse M, Kroth PG, Kottke T (2013) Blue-light-induced unfolding of the $\mathrm{J} \alpha$ helix allows for the dimerization of aureochrome-LOV from the diatom Phaeodactylum tricornutum. Biochemistry 52(18): 3094-3101.

27. Huysman MJJ, Fortunato AE, Matthijs M, Schellenberger Costa B, Vanderhaeghen $\mathrm{R}$ et al. (2013) AUREOCHROME1a-mediated induction of the diatom-specific Cyclin dsCYC2 controls the onset of cell division in diatoms (Phaeodactylum tricornutum). Plant Cell 25(1): 215-228.

28. Schellenberger Costa B, Jungandreas A, Jakob T, Weisheit W, Mittag M et al. (2013) Blue light is essential for high light acclimation and photoprotection in the diatom Phaeodactylum tricornutum. Journal of experimental botany 64(2): 483-493.

29. Guindon S, Dufayard J-F, Lefort V, Anisimova M, Hordijk W et al. (2010) New algorithms and methods to estimate Maximum-Likelihood phylogenies: assessing the performance of PhyML 3.0. Systematic Biology 59(3): 307-321.

30. Le SQ Gascuel O (2008) An improved general amino acid replacement matrix. Molecular Biology and Evolution 25(7): 1307-1320.

31. Guillard RR, Lorenzen CJ (1972) Yellow-green algae with chlorophyllide $c$. Journal of Phycology 8(1): 10-14.

32. Mullis K, Faloona F, Scharf S, Saiki R, Horn G et al. (1986) Specific enzymatic amplification of DNA in vitro - the polymerase chain-reaction. Cold Spring Harbor Symposia on Quantitative Biology 51: 263-273.

33. Zaslavskaia LA, Lippmeier JC, Kroth PG, Grossman AR, Apt KE (2000) Transformation of the diatom Phaeodactylum tricornutum (Bacillariophyceae) with a variety of selectable marker and reporter genes. Journal of Phycology 36(2): 379386. 
34. Gruber A, Vugrinec S, Hempel F, Gould SB, Maier U-G et al. (2007) Protein targeting into complex diatom plastids: functional characterisation of a specific targeting motif. Plant Molecular Biology 64(5): 519-530.

35. Kroth PG (2007) Genetic transformation: a tool to study protein targeting in diatoms. Methods in molecular biology (Clifton, NJ) 390: 257-267.

36. Stork S, Moog D, Przyborski JM, Wilhelmi I, Zauner S et al. (2012) Distribution of the SELMA translocon in secondary plastids of red algal origin and predicted uncoupling of ubiquitin-dependent translocation from degradation. Eukaryotic Cell 11(12): 1472-1481.

37. Poulsen N, Chesley PM, Kröger N (2006) Molecular genetic manipulation of the diatom Thalassiosira pseudonana (Bacillariophyceae). Journal of Phycology 42(5): 1059-1065.

38. Poulsen N, Kröger N (2005) A new molecular tool for transgenic diatoms Control of mRNA and protein biosynthesis by an inducible promoter-terminator cassette. Febs Journal 272(13): 3413-3423.

39. Laemmli UK (1970) Cleavage of structural proteins during assembly of head of bacteriophage-T4. Nature 227(5259): 680-685.

40. Gallagher S, Chakavarti D (2008) Immunoblot analysis. Journal of visualized experiments : JoVE(16).

41. Gilbert M, Wilhelm C, Richter M (2000) Bio-optical modelling of oxygen evolution using in vivo fluorescence: Comparison of measured and calculated photosynthesis/irradiance (P-I) curves in four representative phytoplankton species. Journal of Plant Physiology 157(3): 307-314.

42. Wagner H, Jakob T, Wilhelm C (2006) Balancing the energy flow from captured light to biomass under fluctuating light conditions. New Phytologist 169(1): 95108.

43. Jeffrey SW, Humphrey GF (1975) New spectrophotometric equations for determining chlorophylls $a, b, c 1$ and $c 2$ in higher plants, algae and natural phytoplankton. Biochemie und Physiologie der Pflanzen 167(2): 191-194.

44. Su W, Jakob T, Wilhelm C (2012) The impact of non-photochemical quenching of fluorescence on the photon balance in diatoms under dynamic light conditions. Journal of Phycology 48: 336-346.

45. Bilger W, Bjorkman O (1990) Role of the xanthophyll cycle in photoprotection elucidated by measurements of light-induced absorbency changes, fluorescence and photosynthesis in leaves of Hedera canariensis. Photosynthesis Research 25(3): $173-185$.

46. Ba ANN, Pogoutse A, Provart N, Moses AM (2009) NLStradamus: a simple Hidden Markov Model for nuclear localization signal prediction. Bmc Bioinformatics 10.

47. Bendtsen JD, Nielsen H, von Heijne G, Brunak S (2004) Improved prediction of signal peptides: SignalP 3.0. Journal of Molecular Biology 340(4): 783-795.

48. Lavaud J, Materna AC, Sturm S, Vugrinec S, Kroth PG (2012) Silencing of the violaxanthin de-epoxidase dene in the diatom Phaeodactylum tricornutum reduces diatoxanthin synthesis and non-photochemical quenching. Plos One 7(5).

49. Lepetit B, Volke D, Gilbert M, Wilhelm C, Goss R (2010) Evidence for the existence of one antenna-associated, lipid-dissolved and two protein-bound pools of diadinoxanthin cycle pigments in diatoms. Plant Physiology 154(4): 19051920 .

50. Schumann A, Goss R, Jakob T, Wilhelm C (2007) Investigation of the quenching efficiency of diatoxanthin in cells of Phaeodactylum tricornutum (Bacillariophyceae) with different pool sizes of xanthophyll cycle pigments. Phycologia 46(1): 113-117.

51. Anning T, MacIntyre HL, Pratt SM, Sammes PJ, Gibb S et al. (2000) Photoacclimation in the marine diatom Skeletonema costatum. Limnology and Oceanography 45(8): 1807-1817.
52. Beer A, Juhas M, Buechel G (2011) Influence of different light intensities and different iron nutrition on the photosynthetic apparatus in the diatom Cyclotella meneghiniana (Bacillariophyceae). Journal of Phycology 47(6): 1266-1273.

53. Bailleul B, Rogato A, de Martino A, Coesel S, Cardol P et al. (2010) An atypical member of the light-harvesting complex stress-related protein family modulates diatom responses to light. Proceedings of the National Academy of Sciences of the United States of America 107(42): 18214-18219.

54. Nymark M, Valle KC, Brembu T, Hancke K, Winge P et al. (2009) An integrated analysis of molecular acclimation to high light in the marine diatom Phaeodactylum tricornutum. Plos One 4(11).

55. Sturm S, Engelken J, Gruber A, Vugrinec S, Kroth PG et al. (2013) A novel type of light-harvesting antenna protein of red algal origin in algae with secondary plastids. BMC Evolutionary Biology 13(159): doi:10.1186/1471-2148-11131159 .

56. Lepetit B, Sturm S, Rogato A, Gruber A, Sachse M et al. (2013) High light acclimation in the secondary plastids containing diatom Phaeodactylum tricornutum is triggered by the redox state of the plastoquinone pool. Plant Physiology 161(2): 853-865.

57. Nymark M, Valle KC, Hancke K, Winge P, Andresen K et al. (2013) Molecular and photosynthetic responses to prolonged darkness and subsequent acclimation to re-illumination in the diatom Phaeodactylum tricornutum. PLoS ONE 8(3).

58. Beel B, Prager K, Spexard M, Sasso S, Weiss D et al. (2012) A flavin binding cryptochrome photoreceptor responds to both blue and red light in Chlamydomonas reinhardtii. Plant Cell 24(7): 2992-3008.

59. Jaedicke K, Lichtenthaeler AL, Meyberg R, Zeidler M, Hughes J (2012) A phytochrome-phototropin light signaling complex at the plasma membrane. Proceedings of the National Academy of Sciences of the United States of America 109(30): 12231-12236.

60. Kasahara M, Kagawa T, Sato Y, Kiyosue T, Wada M (2004) Phototropins mediate blue and red light-induced chloroplast movements in Physcomitrella patens. Plant Physiology 135(3): 1388-1397.

61. Lariguet P, Schepens I, Hodgson D, Pedmale UV, Trevisan M et al. (2006) PHYTOCHROME KINASE SUBSTRATE 1 is a phototropin 1 binding protein required for phototropism. Proceedings of the National Academy of Sciences of the United States of America 103(26): 10134-10139.

62. Tsuchida-Mayama T, Sakai T, Hanada A, Uehara Y, Asami T et al. (2010) Role of the phytochrome and cryptochrome signaling pathways in hypocotyl phototropism. Plant J 62(4): 653-662.

63. Kami C, Hersch M, Trevisan M, Genoud T, Hiltbrunner A et al. (2012) Nuclear phytochrome A signaling promotes phototropism in Arabidopsis. Plant Cell 24(2): 566-576.

64. Han I-S, Tseng T-S, Eisinger W, Briggs WR (2008) Phytochrome A regulates the intracellular distribution of phototropin 1-green fluorescent protein in Arabidopsis thaliana. Plant Cell 20(10): 2835-2847.

65. Demarsy E, Schepens I, Okajima K, Hersch M, Bergmann S et al. (2012) Phytochrome Kinase Substrate 4 is phosphorylated by the phototropin 1 photoreceptor. Embo Journal 31(16): 3457-3467.

66. Lopez-Figueroa F, Niell FX (1989) Red-light and blue-light photoreceptors controlling chlorophyll $a$ synthesis in the red alga Porphyra umbilicalis and in the green alga Ulva rigida. Physiologia Plantarum 76(3): 391-397.

67. Ashworth J, Coesel S, Lee A, Armbrust EV, Orellana MV et al. (2013) Genomewide diel growth state transitions in the diatom Thalassiosira pseudonana. Proceedings of the National Academy of Sciences 110(18): 7518-7523. 